\title{
Volatility Integration of Global Stock Markets with the Malaysian Stock Market: A Multivariate GARCH Approach
}

\author{
Peh Ying Qian \\ John Francis Diaz \\ Chung Yuan Christian University
}

\begin{abstract}
The research studies short- and long-run volatility dynamics between Malaysia's stock market and 14 developed and developing major stock markets in the five different regions of America, Europe, Africa, Asia and Oceania. The paper uses three multivariate generalised autoregressive conditional heteroscedasticity (MGARCH) models, namely, the Baba, Engle, Kraft and Kroner (BEKK) model; constant conditional correlation (CCC) model; and the dynamic conditional correlation (DCC) model to examine volatility relationship of different stock markets to the Malaysian stock market. Findings show that the long-term volatility relationship of Malaysia's Kuala Lumpur Stock Exchange Index's volatility with the UK's FTSE 100, Germany's DAX and France's CAC 40 found in the CCC and DCC models is a result of a long-term free trade agreement signed between Malaysia and the European countries. Unstable volatility relationship is found between Malaysia and China's stock markets. Similar situations are observed in Malaysia's steady or unstable economic relationships with the other countries stock markets, which can be either a product of strong trading and investing partnerships or political and social conflicts. The BEKK model confirms these volatility spillovers, and concludes that volatilities are not only determined by their own lagged values, but cross-volatility spillovers from other countries also exist. Results show that most of the stock indices have significant spillover effects on the stock market of Malaysia, which confirms evidence of growing market integration. In general, a study on volatility transmission plays an important role in identifying vulnerabilities of certain stock markets against other markets, which helps in determining better investing decisions that can minimise losses, and can even improve returns depending on the hedged position taken by the investor.
\end{abstract}

Keywords: Bursa Malaysia, global stock markets, MGARCH, stock market returns, volatility transmission

JEL classification: F36, G15

\section{Introduction}

The Malaysian financial system has transformed into becoming one of the major financial centres in the ASEAN region. In the midst of stronger economic and financial integration, Malaysia's financial sector is playing a more prominent role in intermediating financial resources in the region and in other emerging and developed economies. The financial system's efficient management of monetary resources

\footnotetext{
a International Master of Business Administration Program, College of Business, Chung Yuan Christian University, Chung-li City, Taiwan. Email: iris08138@gmail.com

b Department of Finance and Department of Accounting, College of Business, Chung Yuan Christian University, Chung-li, Taiwan. Email: di.jiang@cycu.edu.tw, johnfrancis_diaz@yahoo.com (Corresponding author)
} 
transformed the country into becoming a high-income and high value-added economy. This led the financial markets into having a more diversified and stable financial system.

The Central Bank of Malaysia aims to transform the country into a financial hub of Asia (Ibrahim, 2010). Malaysia's financial market is regulated by Bursa Malaysia or Malaysian Stock Exchange, which was previously known as the Kuala Lumpur Stock Exchange. The Kuala Lumpur Stock Exchange Composite Index (KLSE) is the main index for Bursa Malaysia. While most of the securities and derivatives were traded through Bursa Malaysia, it also plays the role of vanguard in the fair and orderly Malaysian capital market.

The market capitalisation of Bursa Malaysia amounted to US\$156 billion at the end of 2012. Figure 1 shows the steady growth that Bursa Malaysia experienced from 2003 to 2012. The decline during 2008 was due to the subprime mortgage crisis, which was a systemic problem experienced by all countries. In 2006, Bursa Malaysia first partnered with FTSE to provide a collection of indices to enhance market performance and to offer a selection of benchmark indices. The FTSE Bursa Malaysia KLSE Index comprises of the largest 30 companies by market capitalisation, including the famous Resorts World Genting, Hong Leong Bank and Petronas.

According to UNCTAD (2014), although Malaysia's foreign direct investment (FDI) inflow ranks only fourth among the ASEAN economies, the net FDI inflows grew impressively by 22.2 percent to US\$12.3 billion (RM39.6 billion) in 2013, compared with US\$10.1 billion in the previous year. This means that Malaysia is an attractive country to investors just behind Singapore, Indonesia and Thailand. In terms of percentage in GDP, the average value from 1970 to 2013 was 3.76 percent with a minimum of 0.06 percent in 2009 and a maximum of 8.76 percent in 1992. According to the global economic report of UNCTAD, the total inflow of FDI in year 2013 accounted for 3.71 percent of Malaysia's GDP. Based on a study by Ang (2008), the Malaysian real GDP

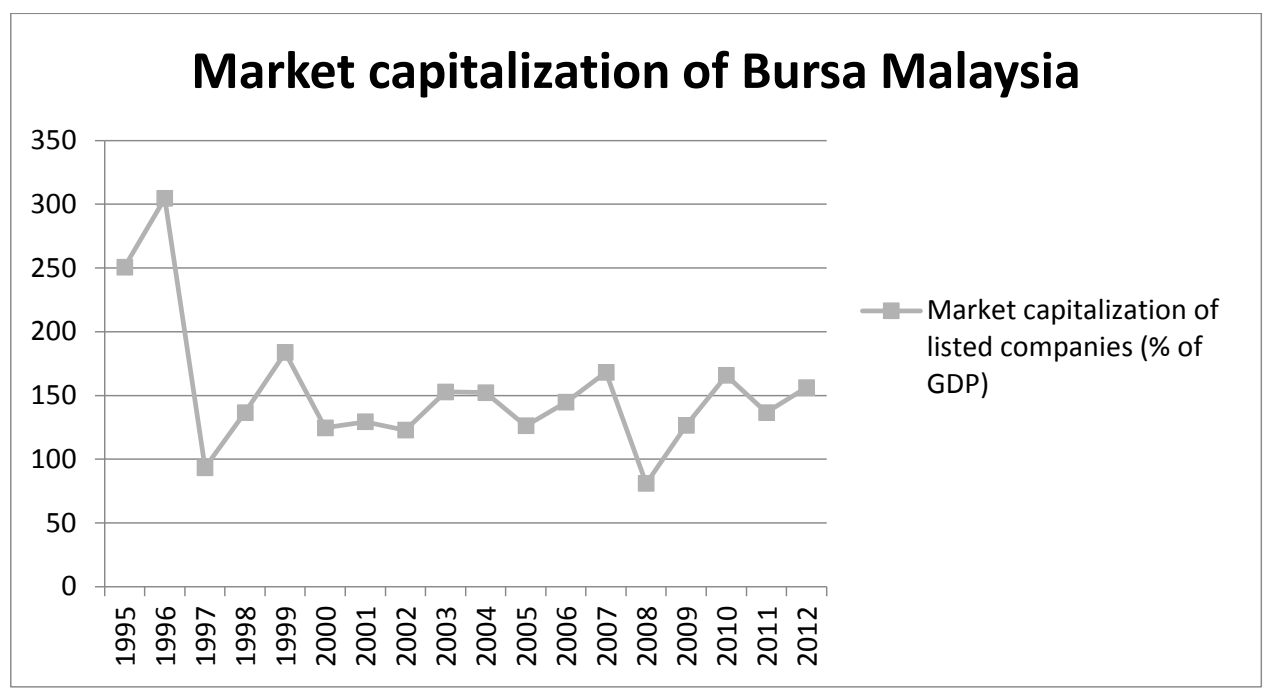

Figure 1: Market capitalization of Bursa Malaysia Source: World Federation of Exchanges Database, World Data Bank 2013. 
has a significant positive impact on the inflow of FDI, and the increase in financial development, infrastructure development and trade openness also promote FDI.

On the other hand, foreign portfolio investments (FPI) inflow, which go directly to Malaysia's financial markets amounted US\$18.93 billion in 2012, according to data retrieved from the World Bank. Duasa and Kassim (2008) provided good insights on the mixed effect of FPIs on the Malaysian financial markets and economy using the Granger causality test. The authors found that FPIs from the UK and Singapore contribute positively; however, FPIs from the US and Hong Kong negatively impact the economic growth and financial markets of Malaysia. A similar study was also done by Lean and Teng (2013) using multivariate generalised autoregressive conditional heteroscedasticity (MGARCH) models to study the volatility impacts of the US, Japan, China and Indian stock markets on the Malaysian financial market. The study found that there is strong financial integration between the stock markets of Malaysia with Japan, India and China, while a waning volatility spillover effect was observed with the US because of the strengthening regional integration in Asia.

This paper expands the existing literature by applying MGARCH models to better capture the short- and long-run volatility dynamics. This research expands its data by including stock markets from five different regions such as America, Europe, Africa, Asia and Oceania in order to examine a more global volatility relationship among different stock markets to the Malaysian financial market instead of focusing only on the US and major Asian stock markets. The power of MGARCH model lies in determining an asset's volatility transmission to another asset directly through its conditional variances; and indirectly through its conditional covariance. MGARCH models are formulated to model volatility relationships between two time-series data, which offer relevant information on risk measures and spillovers. Bollerslev (1990) introduced the first MGARCH model through the constant conditional correlation (CCC) model. The CCC model improves the estimates by using non-parametric models, and by extending the correlation to a more adaptive model. Engle and Kroner (1995) proposed the second MGARCH model through the synthesized Baba, Engle, Kraft and Kroner (BEKK) model, which allows cross dynamics of conditional covariance. Engle (2002) augmented a constrained dynamism in the correlations through the dynamic conditional correlation (DCC) model to capture changes in the short- and long-run volatility persistence.

The research is motivated by limited empirical studies using a combination of the three MGARCH models in looking at volatility linkages of major stock markets around the globe with the Malaysian stock market. The study is also inspired by the continuously growing financial market of Malaysia and its importance as a financial trading hub over the last decade. This has been brought about by the growing integration among global economies because of signed trade agreements among its trading partners. Another motivation is that from the financial regulator's perspective, increased integration leads to higher volatility which requires stronger structural and regulatory adjustments if necessary. This is also a way to strengthen the economy and financial markets in the face of greater volatility regimes which may lead to economic and financial crises if remained uncontrolled for a longer period.

The focus of this paper on Malaysia is an interesting subject due to the rich history of the economy's financial reform which leaves a strong effect on the economic 
structure of the country. The purpose of the study is to provide an examination on the impact of major global stock markets and regional stock markets on the Malaysian financial market, and vice versa. The power of multivariate GARCH (MGARCH) models in analysing the co-movements of financial stock volatilities made this paper apply the methodology. It is always essential to estimate, construct, evaluate and forecast the covolatility dynamics of financial asset returns of portfolios, and these can be substantially fulfilled by the application of MGARCH models. This paper analyses the volatility relationship of fifteen major stock markets with the Malaysian stock market, using three multivariate volatility models, namely diagonal BEKK, CCC, and DCC; and compares the performances of these models to identify which of the multivariate methods considered is best to model the stock markets relations.

The study fulfils a gap in the literature of Malaysia's financial markets like: a) the use of diverse multivariate models to examine volatility relationship; b) the changes (i.e., short- vs. long-run) in the volatility transmission; and c) the degree of integration (i.e., stronger or weaker) with the major financial markets and its trading partners. This paper contributes to the literature by expanding the volatility relationship of the major global stock markets with Malaysia, and augmenting the literature on volatility dynamics using MGARCH models. The main objectives of this research are to: (i) identify the presence of long- and short-run persistence on the relationship of the 14 major stock markets with the Kuala Lumpur Stock Exchange, (ii) determine if the volatility relationship is transmitted within the markets through their own conditional variances or through their conditional covariances, (iii) examine if volatility is constant or varies over time, and (iv) identify which multivariate model can best determine the relationship among the major global stock markets and KLSE.

This paper is divided in four sections. Section 2 reviews the related literature. Section 3 presents the data and explains the methodologies of the paper. The last section provides the conclusion and limitations of the paper, and recommendations for future studies.

\section{Literature Review}

Globalisation and the growing regionalisation made the world's economy more integrated and interdependent creating positive and negative innovations with no regard to physical boundaries. The study on Malaysia's bilateral trade relationship by Yusoff (2005) suggested bi-directional linkage with Singapore, as Malaysian exports have caused imports from Singapore to increase. Regarding the relationship of Malaysia to the US, the recent study of Rinehart (2014) supports the claim of the earlier study by identifying Malaysia as the top 18 in the main suppliers of US imports and top 25 largest market for US exports, while the US is Malaysia's top 4 largest export markets and also ranked top 4 in the main suppliers of Malaysian imports in year 2013. The expanding influence of regionalisation cannot also be discounted, Patel (2013) showed the integration between India with other Asian equity markets, from Sri Lanka, Korea, China and Singapore; specifically, the study finds that the Indian stock market has a unidirectional effect on the Pakistani stock market.

The spillovers of returns and volatility among closer geographical territories are more evident in the literature like the recent study of Krause and Tse (2013) who 
discovered bi-directional relationship between the stock markets of the US and Canada. This was also proven by the studies of Singh, Kumar and Pandey (2010) and Miyakoshi (2003) when they discovered that Asian market volatility is influenced by Japan's financial market more than that of the US. Worthington and Higgs (2004) also indicated that volatility integrations across Asian stock markets are statistically significant, as well as own-volatility spillover effects are higher than cross-volatility spillover across the countries' stock markets, especially in the emerging economies. A unique finding of Yilmaz (2010) showed that spillovers of volatility and returns across East Asian equity markets behave very differently from time to time, during crisis and non-crisis periods, with burst in volatility spillover rather than returns spillover during the major crisis period. The effects of crises periods were also observed by Zhou, X., Zhang, W. and Zhang, J. (2012) and Allen, Amram and McAleer (2013) who showed a little evidence of volatility spillover effects from the Chinese stock markets to the US stock markets during the global financial crisis (GFC) period, but no evidence of spillover effects found in the post-GFC period. Korkmaz, Çevik and Atukeren (2012) also studied a group of countries called CIVET countries (i.e., Columbia, Indonesia, Vietnam, Egypt, Turkey and South Africa) and found the existence of intraregional and interregional returns and volatility spillover effects among the economies. Furthermore, the research of Singh, Kumar and Pandey (2008) revealed high correlation among the European markets region, as well as the influence from Japan, South Korea, Singapore and Hong Kong stock markets, while the US market is influenced by both European and Asian markets.

The literature has also shown wide applicability of MGARCH methodologies on the linkages of international equity markets. A recent study of Alotaibi and Mishra (2015) utilising BEKK, CCC and DCC models indicated significant local spillover effects in all five GCC (Bahrain, Oman, Kuwait, Qatar and the United Arab Emirates) markets, while the regional spillover influence from Saudi Arabia also appear to positively influence Kuwait, Oman, Qatar and the United Arab Emirates, but negatively affects Bahrain. The study of Thao, Daly and Ellis (2013) using GARCH-BEKK, CCC and DCC models also discovered that Japan was most influenced by spillover effects from the US during the GFC period, and the impact are likely to transmit to East Asian countries via Japan. Another related study of Wang and Moore (2008) using the DCC-EGARCH model showed statistically significant dynamic linkage between three emerging countries in the Eurozone markets during crisis and increased correlation during the post-crisis period. The study of Majdoub and Mansour (2014) used three multivariate GARCH models including BEKK, CCC and DCC to examine the dynamic correlation of volatility of the US market with five Islamic emerging markets including Turkey, Indonesia, Pakistan, Qatar and Malaysia. The GARCH-BEKK results revealed the weak volatility correlation in all country-pairs, which suggest the weak linkage between US and Islamic emerging markets. However, the CCC and DCC models showed low correlation integration over time, which suggest the weak integration across markets and low influence of US markets on the Islamic emerging markets.

The above literature demonstrated that volatility transmissions happen in global and regional financial markets, and volatility persistence can be constant over time or can also become dynamic and constantly changing depending on market characteristics and shocks like financial crises or economic depressions. 


\section{Data and Methodology}

The list of indices paired with the KLSE index of Malaysia are the S\&P 500 and Dow Jones Industrial Average (DOW) indices of the US, Toronto Stock Exchange (TSX) index of Canada, Financial Times and the London Stock Exchange (FTSE 100) of the UK, Deutscher Aktienindex (DAX) of Germany, Cotation Assistée en Continu (CAC 40) of France, Johannesburg Stock Exchange (JSE) of South Africa, Egyptian Exchange (EGX 30) index, Nigerian Stock Exchange (NGE 30) index, Australian Securities Exchange (ASX) index, New Zealand Exchange (NZS) index, Shanghai Stock Exchange (SSEC) of China, Bombay Stock Exchange (BSE) of India and Nikkei Heikin Kabuka (NIKKEI) of Japan. According to the World Bank's data of 2013, total market capitalisation of KLSE amounted to around US\$476 billion, S\&P500 and Dow is approximately US\$18,668 billion, TSX is around US\$2,016 billion, FTSE 100 is around US\$3,019 billion, DAX is approximately US\$1,486 billion, CAC 40 is around US\$1,823 billion, JSE is approximately US\$612 billion, EGX 30 is around US\$58 billion, NGE 30 is approximately US\$56 billion, ASX is around US\$1,286 billion, NZX is approximately US\$80 billion, SSEC is around US\$3,697 billion, India is around US\$1,263 billion and Japan is approximately US\$3,681 billion. This study uses daily closing prices retrieved from the Taiwan Economic Journal (TEJ) database starting from January 1999 or the year when Asian economies have already recovered from the Asian financial crisis, until January 2015. The study picked the major stock markets in each continent, which has trading relations with Malaysia in terms of FDIs and FPIs.

This part of the paper expounds the three MGARCH models, which are applicable to constant conditional correlations (CCC model) and dynamic conditional correlations (DCC and BEKK models), and are adapted on the discussions provided by Chang, McAleer and Tansuchat (2011).

\subsection{Constant Conditional Correlations Model}

The CCC multivariate GARCH model was proposed by Bollerslev (1990) and offers better estimates by utilising non-parametric models and by having a more suitable model for the constant conditional correlation. CCC can be represented below:

$$
\begin{aligned}
& y_{t}=E\left(y_{t} \mid F_{t-1}\right)+\varepsilon_{t}, \varepsilon_{t}=D_{t} \eta_{t}, \\
& \operatorname{var}\left(\varepsilon_{t} \mid F_{t-1}\right)=D_{t} \Gamma D_{t}
\end{aligned}
$$

where $y_{t}=\left(y_{1 t, \ldots,}, y_{m t}\right)^{\prime}, \eta_{t}=\left(\eta_{1 t, \ldots,}, \eta_{m t}\right)^{\prime}$ denotes a series of independently and identically distributed (iid) random vectors of stock returns, $F_{t-1}$ represents the previous available information at particular time $t, D_{t}=\operatorname{diag}\left(h_{1}^{1 / 2}, \ldots, h_{m}^{1 / 2}\right)$ means a diagonal matrix of conditional variances.

McAleer (2005) and Bauwens, Laurent and Rombouts (2006) further expanded the model in the constant conditional correlation matrix of the unconditional shocks giving $\eta_{t}$ equal to the constant conditional covariance matrix of the conditional shocks, $\varepsilon_{t}$, 
from Eq. (1). Note that $\varepsilon_{t} \varepsilon_{t}^{\prime}=D_{t} \eta_{t} \eta_{t}^{\prime} D_{t}, D_{t}=\left(\operatorname{diag} Q_{t}\right)^{1 / 2}$ and $E\left(\varepsilon_{t} \varepsilon_{t}^{\prime} \mid F_{t-1}\right)=Q_{t}=D_{t} \Gamma D_{t}$ with $\Gamma=E\left(\eta_{t} \eta_{t}^{\prime} \mid F_{t-1}\right)=E\left(\eta_{t} \eta^{\prime}\right)$ where $\Gamma=\left\{\rho_{i j}\right\}$ for $\mathrm{i}, \mathrm{j}=1, \ldots, \mathrm{m} . Q_{t}$ stands for the conditional covariance matrix, which is a positive definite if all the conditional variances are positive and $\Gamma$ is positive.

The assumption of a constant conditional variance for each return, $h_{i t}, i=1, \ldots, m$, is a univariate $\mathrm{GARCH}$ process and is represented as:

$$
h_{i t}=\omega_{i}+\sum_{j=1}^{r} \alpha_{i j} \varepsilon_{i, t-j}^{2}+\sum_{j=1}^{s} \beta_{i j} h_{i, t-j}^{2}
$$

where $\alpha_{i j}$ represents the ARCH effect, or the short run persistence of shocks to return $\mathrm{i}$, $\beta_{i j}$ denotes the GARCH effect, and $\sum_{j=1}^{r} \alpha_{i j}+\sum_{j=1}^{s} \beta_{i j}$ stands for long run persistence.

\subsection{Dynamic Conditional Correlation Models}

The DCC model was proposed by Engle (2002) and generated a time-dependent conditional correlation matrix. The model can be shown in the following form:

$$
\begin{aligned}
& y_{t} \mid F_{t-1}+\varepsilon_{t}, \varepsilon_{t}=D_{t} \eta_{t} \sim N\left(0, Q_{t}\right), t=1,2, \ldots, n \\
& Q_{t}=D_{t} \Gamma D_{t}
\end{aligned}
$$

where $D_{t}=\operatorname{diag}\left(h_{1}^{1 / 2}, \ldots, h_{m}^{1 / 2}\right)$ denotes a diagonal matrix of conditional variances, and $F_{t}$ represents the information set at time $t$.

The conditional variance, $h_{i t}$, follows a univariate GARCH model, given as

$$
h_{i t}=\omega_{i}+\sum_{k=1}^{p} \alpha_{i k} \varepsilon_{i, t-k}^{2}+\sum_{l=1}^{q} \beta_{i j} h_{i, t-l}^{2}
$$

Given $\eta_{t}$ as a vector of iid random variables with zero mean and unit variance, $Q_{t}$ in Eq. (4) stands for conditional covariance matrix (after standardisation, $\eta_{i t}=y_{i t} / \sqrt{h_{i t}}$ ). The $\eta_{i t}$ is used to estimate the DCC as below:

$$
\Gamma_{t}=\left\{\operatorname{diag}\left(Q_{t}\right)^{-1 / 2}\right\} Q_{t}\left\{\operatorname{diag}\left(Q_{t}\right)^{-1 / 2}\right\}
$$

where the $\mathrm{k} \times \mathrm{k}$ symmetric positive definite matrix $Q_{t}$ is calculated as:

$$
Q_{t}=\left(1-\theta_{1}-\theta_{2}\right) \bar{Q}+\theta_{1} \eta_{t-1} \eta_{t-1}^{\prime}+\theta_{2} Q_{t-1}
$$

where $\theta_{1}$ and $\theta_{2}$ express the scalar parameters that stands for the effects of past shocks and past dynamic conditional correlations on the present dynamic conditional correlation.

These are also non-negative scalar parameters that fulfil the condition $\theta_{1}+\theta_{2}<1$, which also means that $Q_{t}>0 . Q_{t}$ in Eq. (8) is a conditional covariance matrix, given $\theta_{1}=$ $\theta_{2}=0$, and $\bar{Q}$ is the kxk unconditional variance matrix of $\eta_{t}$. 
The DCC model is non-linear but may be estimated by using a two-step method: (1) utilising a series of univariate GARCH estimate, and (2) adapting a correlation estimate, all based on the likelihood function (Caporin \& McAleer, 2009).

\subsection{Baba, Engle, Kraft and Kroner Model}

The BEKK model was suggested by Engle and Kroner (1995) to adapt with the presence of dynamic conditional correlations. The model has a characteristic that the conditional covariance matrices are definitely positive. The BEKK model for multivariate GARCH $(1,1)$ is shown below:

$$
H_{t}=C^{\prime} C+A^{\prime} \varepsilon_{t-1} \varepsilon_{t-1}^{\prime} A+B H_{t-1} B
$$

The matrices $C, A$ and $B$ 's individual elements are represented as:

$$
A=\left[\begin{array}{l}
a_{11} a_{12} \\
a_{21} a_{22}
\end{array}\right], \quad B=\left[\begin{array}{l}
b_{11} b_{12} \\
b_{21} b_{22}
\end{array}\right], \quad C=\left[\begin{array}{l}
c_{11} 0 \\
c_{21} c_{22}
\end{array}\right]
$$

Given $\sum_{j=1}^{q} \sum_{k=1}^{k}\left(A_{k j} \otimes A_{k j}\right)+\sum_{j=1}^{q} \sum_{k=1}^{k}\left(B_{k j} \otimes B_{k j}\right), \otimes$ denotes the Kronecker product of two matrices, which are less than one in the modulus for covariance stationary (Silvennoinen \& Terasvirta, 2008; Chang et al., 2011). The conditional variances are functions of their lagged values and lagged squared stock value shocks, while the conditional covariances are functions of the lagged covariances and lagged crosscountry of the corresponding stock value shocks from the diagonal formulation. This demonstration ensures that $H_{t}$ is positive definite for all t.

The BEKK $(1,1)$ model has $N(5 N+1) / 2$ parameters (Caporin \& McAleer, 2009). Given the equation $B=A D$ where $D$ is a diagonal matrix, the number of estimated parameters are decreased, and the above equation will be changed to:

$$
H_{t}=C^{\prime} C+A^{\prime} \varepsilon_{t-1} \varepsilon_{t-1}^{\prime} A+D^{\prime} E\left[A^{\prime} \varepsilon_{t-1} \varepsilon_{t-1}^{\prime} A\right] D
$$

where $\alpha_{i i}^{2}+b_{i i}^{2}<1, \mathrm{i}=1,2$ represents a stationary series. The parameters of the covariance equation $\left(h_{i j, t}, i \neq j\right)$ are results of the subsequent parameters of the two variance equations $\left(h_{i j, t}\right)$.

\section{Empirical Results}

Table 1 shows descriptive statistics of daily closing prices of the 15 main stock indices under study. The stock market of South Africa posted the highest average returns with 6.2 percent, followed by India with 5.5 percent, and Nigeria with 5.4 percent. Malaysia's main stock index is in 6th place with 2.9 percent. It can be observed that most of these countries came from emerging African economies. Apparently, none of the stock indices showed negative average returns. The stock market of India posted the highest standard deviation of 1.595, followed by mainland China with 1.593 and Egypt with 1.551. India and mainland China are currently experiencing rapid changes in the economy, while Egypt has been constantly plagued by political turmoil. The three lowest standard 


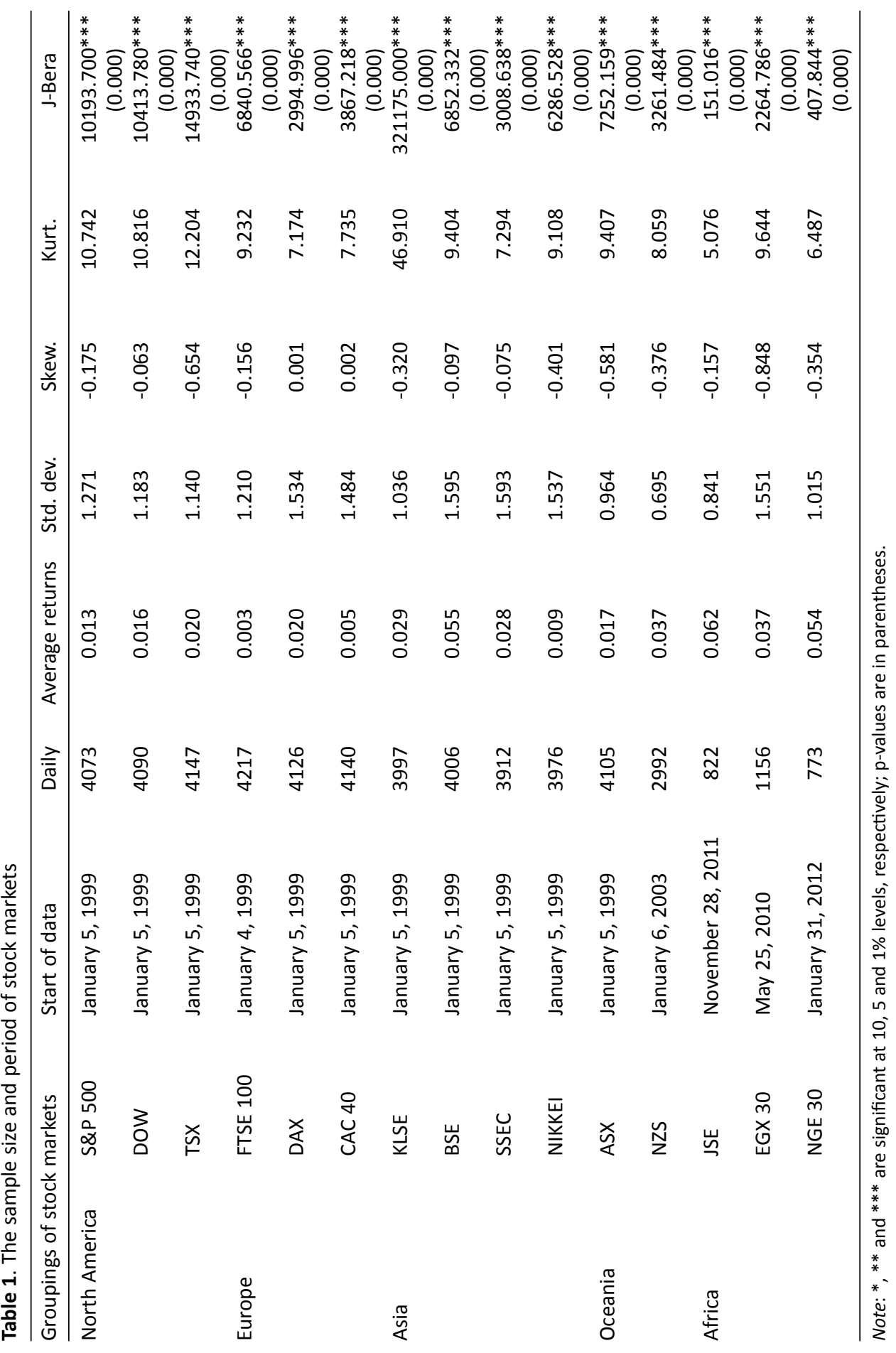


deviations are New Zealand with 0.695, South Africa with 0.841 and Australia with 0.964 . Most of stock prices' returns are negatively skewed with the exception of Germany and France, which is consistent with the relatively high returns experienced by the stock markets under study. All stock prices are leptokurtic, which entails that higher abnormal returns are present in the observations. The significant number of JarqueBera test statistics showed that 15 stock market prices are not normally distributed.

Table 2 illustrates statistics of time-series data using ARMA and GARCH filters. The Augmented Dickey-Fuller (ADF) test was applied initially to check whether the stock market indices are stationary and has no unit. The paper observes that all indices showed significant results at the 1 percent level in the ADF test. The Akaike Information Criterion (AIC) was applied in order to select the best lag length for both ARMA and GARCH models. From the suggested specifications of the lowest AIC, we have chosen the suitable lags. For example, the result of the AIC test showed that lag orders $(2,1)$ are best suited for the KLSE indices in both ARCH and GARCH models. The results also indicated that the null hypothesis of no serial correlation cannot be rejected for all of the stock indices, with the exception of the United Kingdom, France, India and mainland China, through the Lagrange Multiplier (LM) test. To identify the ARCH effect on the stock price indices, the autoregressive conditional heteroscedasticity LM (ARCH-LM) test is used. From the table, results showed the presence of heteroscedasticity problems in all of the stock price indices significant at the 1 percent level. GARCH filters were applied, and the best lag order was determined using the AIC test. After the test, all stock price indices showed insignificant results in the last column, which means that the heteroscedasticity problem was resolved.

\subsection{Constant vs. Dynamic Volatility Linkages}

Table 3 illustrates results of the constant conditional correlation (CCC) model among the country pairings. The lowest AIC again was utilised initially to determine the best fitting lag length for each model. Results demonstrate that most of the best lag order is $(2,2)$, with the exception of the Malaysia-India pair, which is best modelled by the $(1,2)$ order; and Malaysia-Australia, and Malaysia-New Zealand pairings, which are best modelled by $(2,1)$ orders. To verify if the multivariate ARCH effects are present in the indices, the tests proposed by Hosking (1980) and Li and McLeod (1981) were used. Findings showed that most of the indices are applicable for the time-series using CCC, with the exception of Malaysia's volatility pairings with the stock indices of Canada, China, Indonesia, Egypt and Nigeria.

The table further shows that all of the ARCH $(\alpha)$ and $\mathrm{GARCH}(\beta)$ estimations showed significant results, which means long-run persistence does exist among these countries indices with the Malaysian index. For example, the changes and shocks in the volatility series of KLSE can also be affected by the US'S S\&P 500 (0.058) and DOW (0.052), UK'S FTSE (0.167), Germany's DAX (0.144), France's CAC 40 (0.168), Japan's Nikkei (0.330), Australia's ASX (0.311) and New Zealand's NZE (0.219) over the long horizon. The top three stock indices with the strongest effect are the Japan's Nikkei, Australia's ASX and New Zealand's NZE, which all have relatively strong trading relations with the Malaysian market in terms of FDIs and FPIs. Some of these empirical results are significantly 


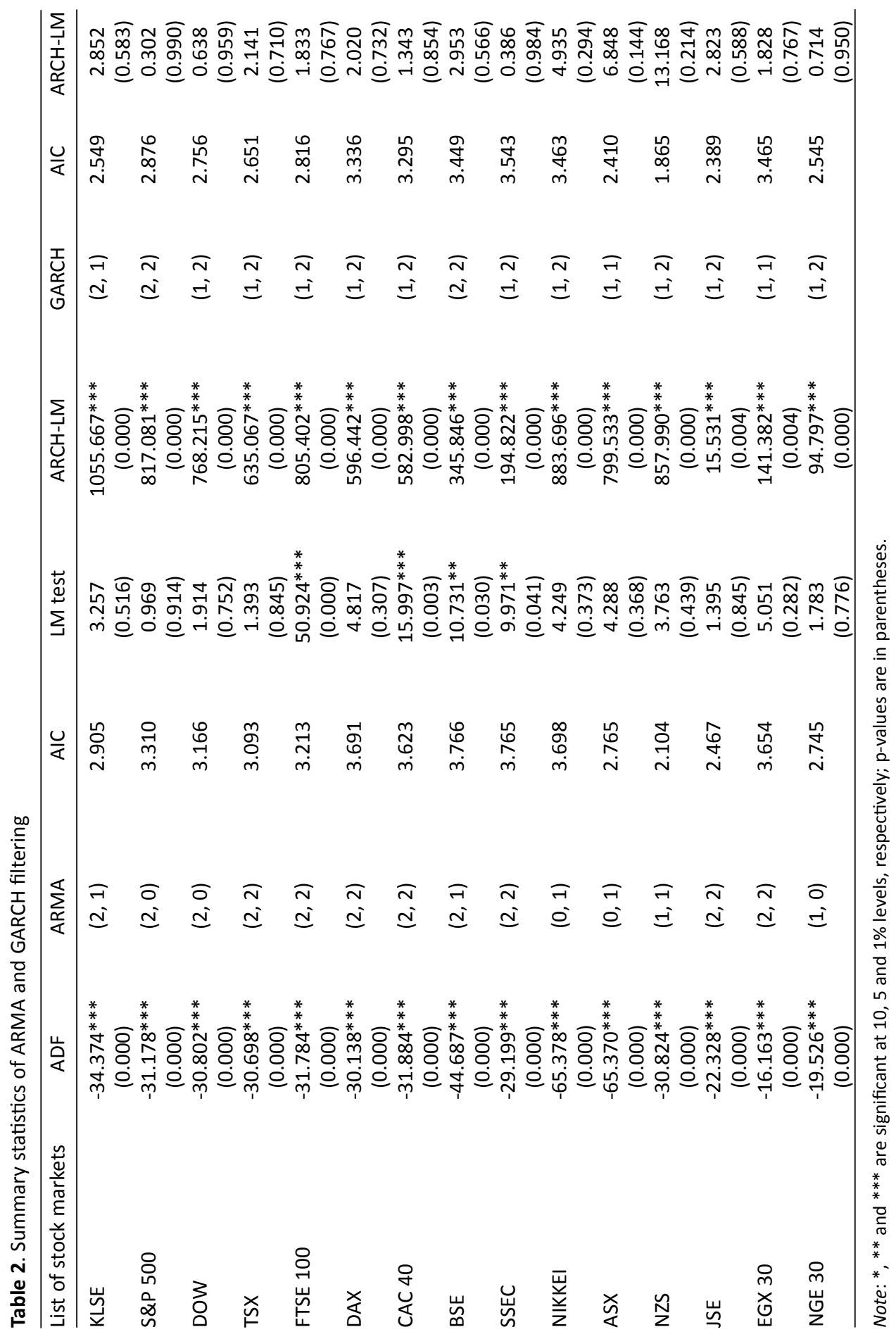


Peh Ying Qian and John Francis Diaz

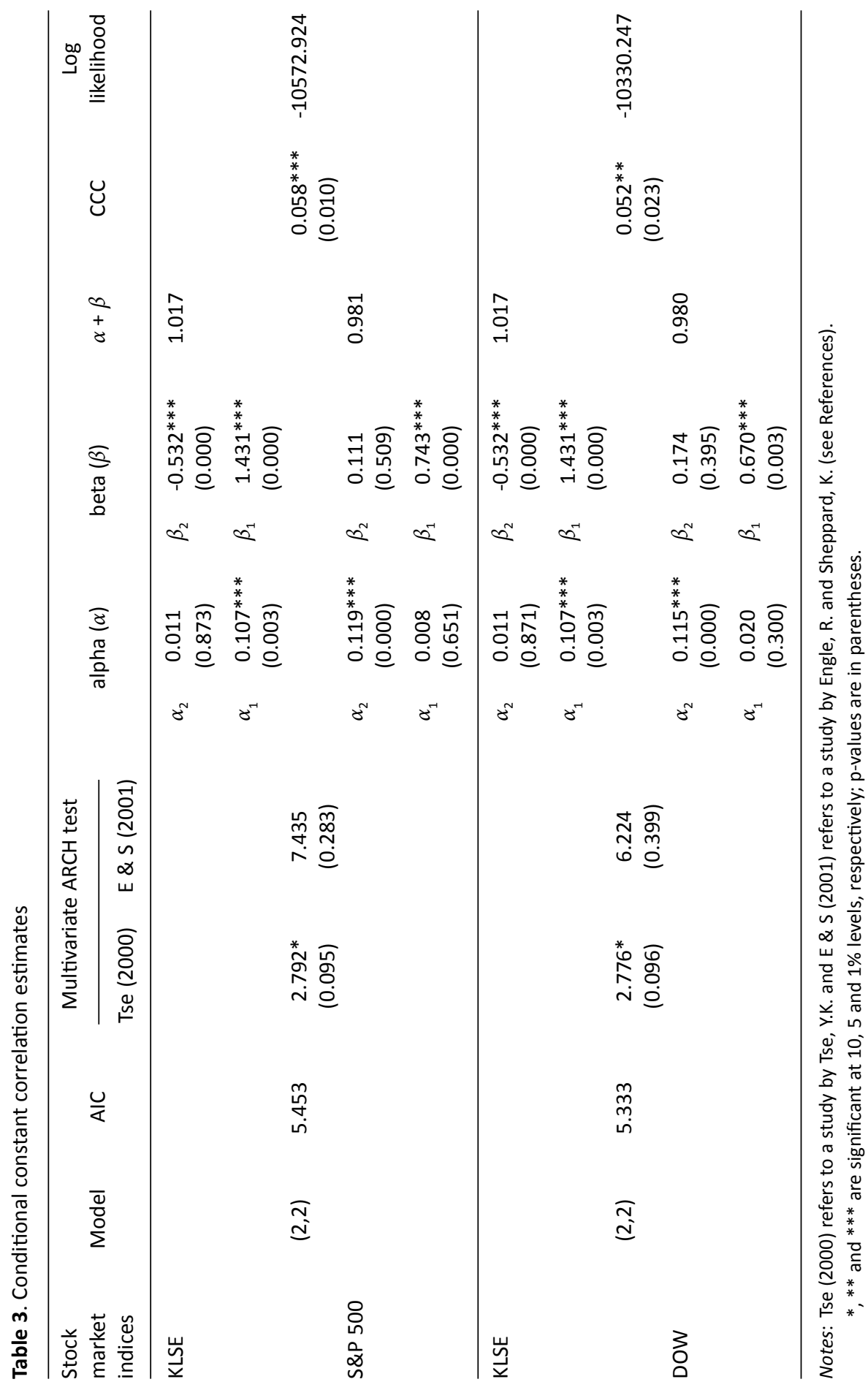


Volatility Integration of Global Stock Markets with the Malaysian Stock Market

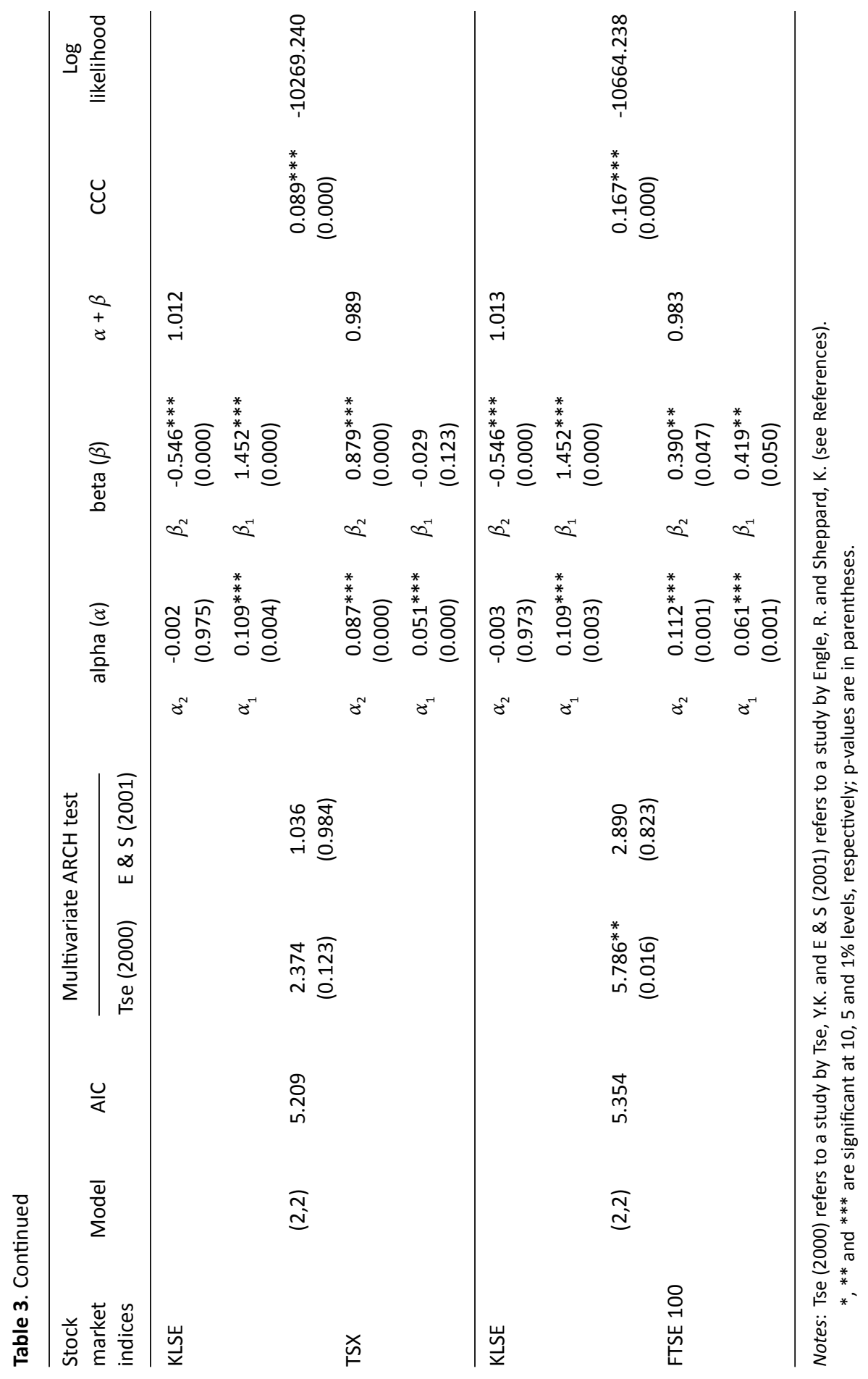


Peh Ying Qian and John Francis Diaz

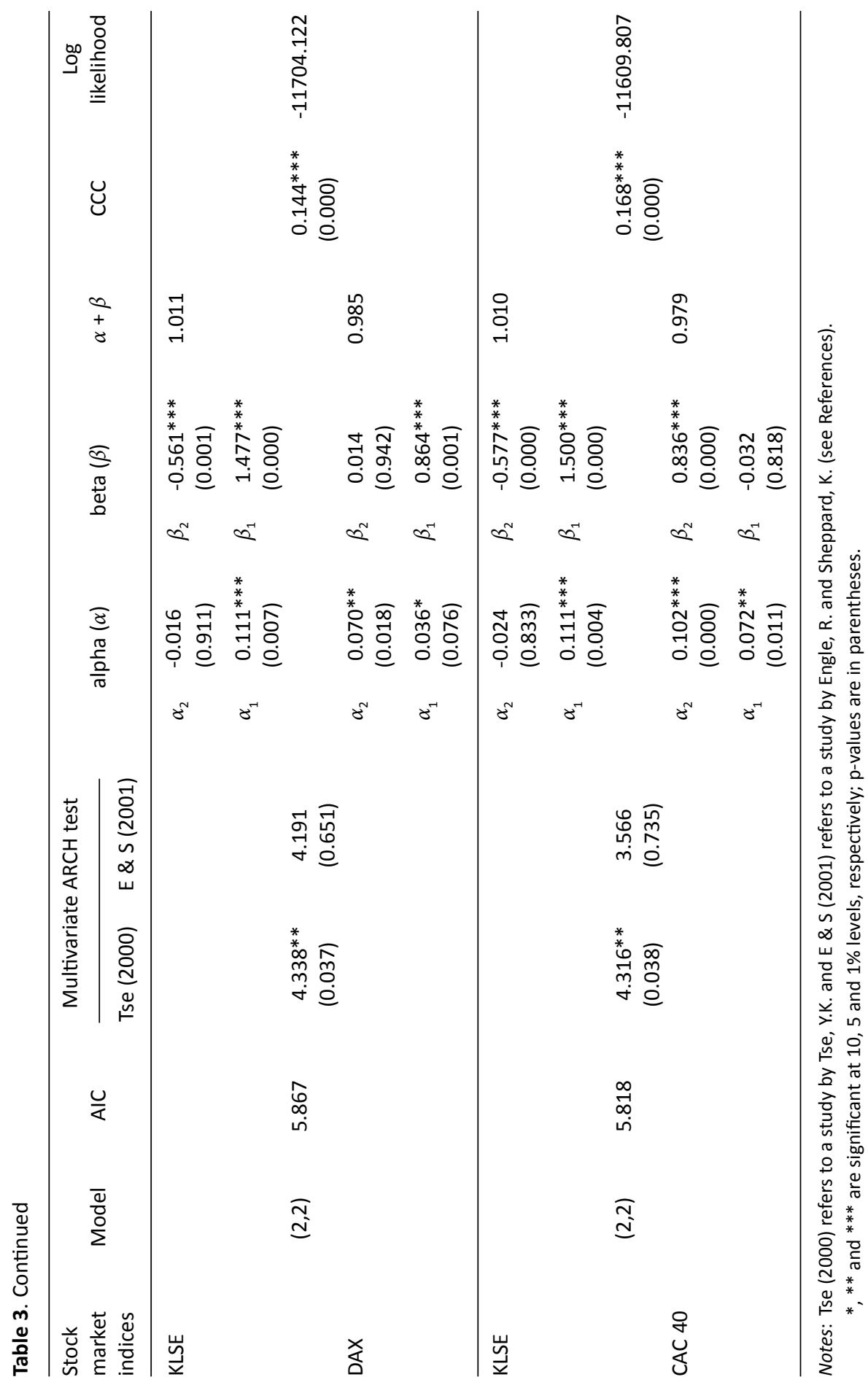


Volatility Integration of Global Stock Markets with the Malaysian Stock Market

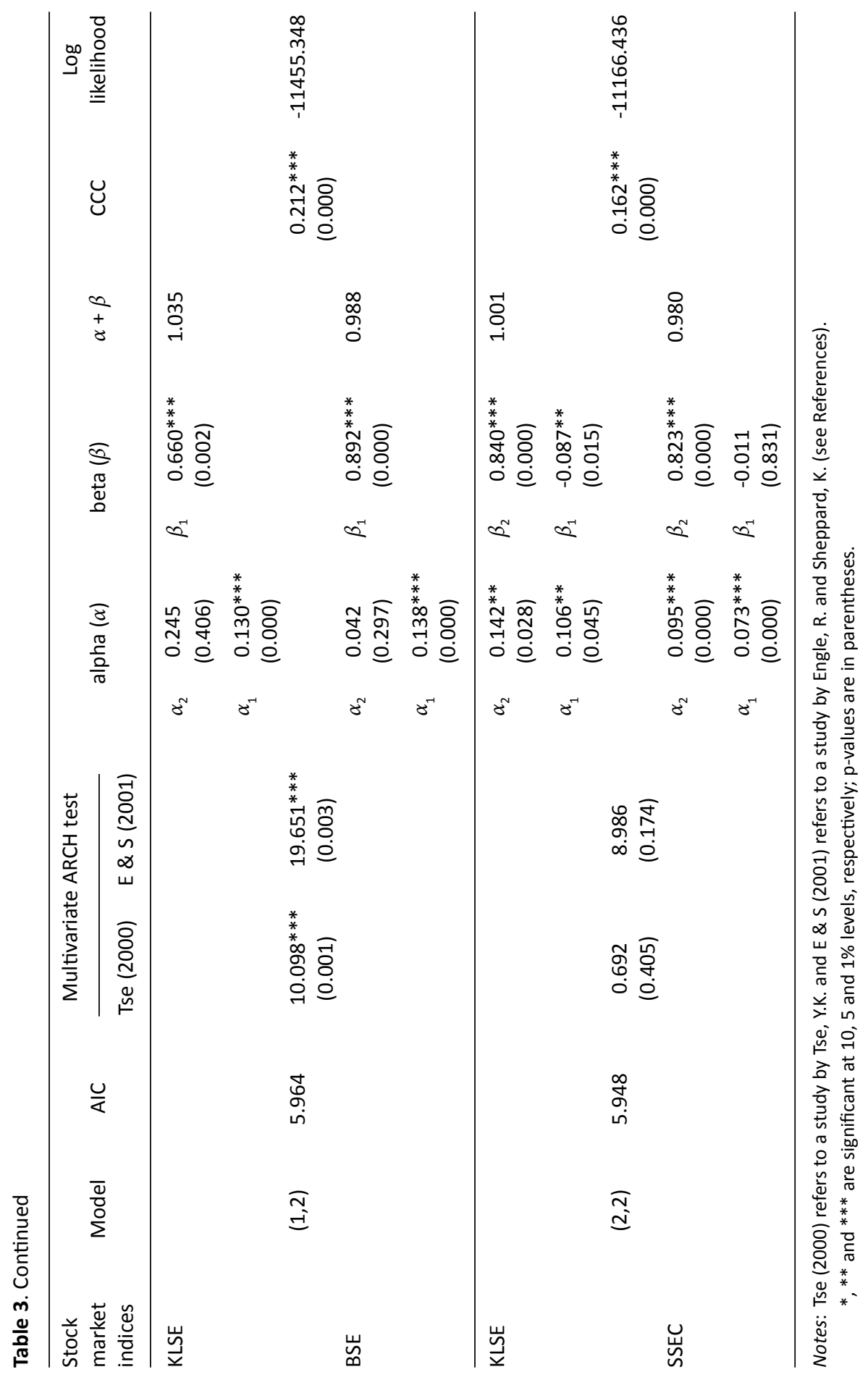


Peh Ying Qian and John Francis Diaz

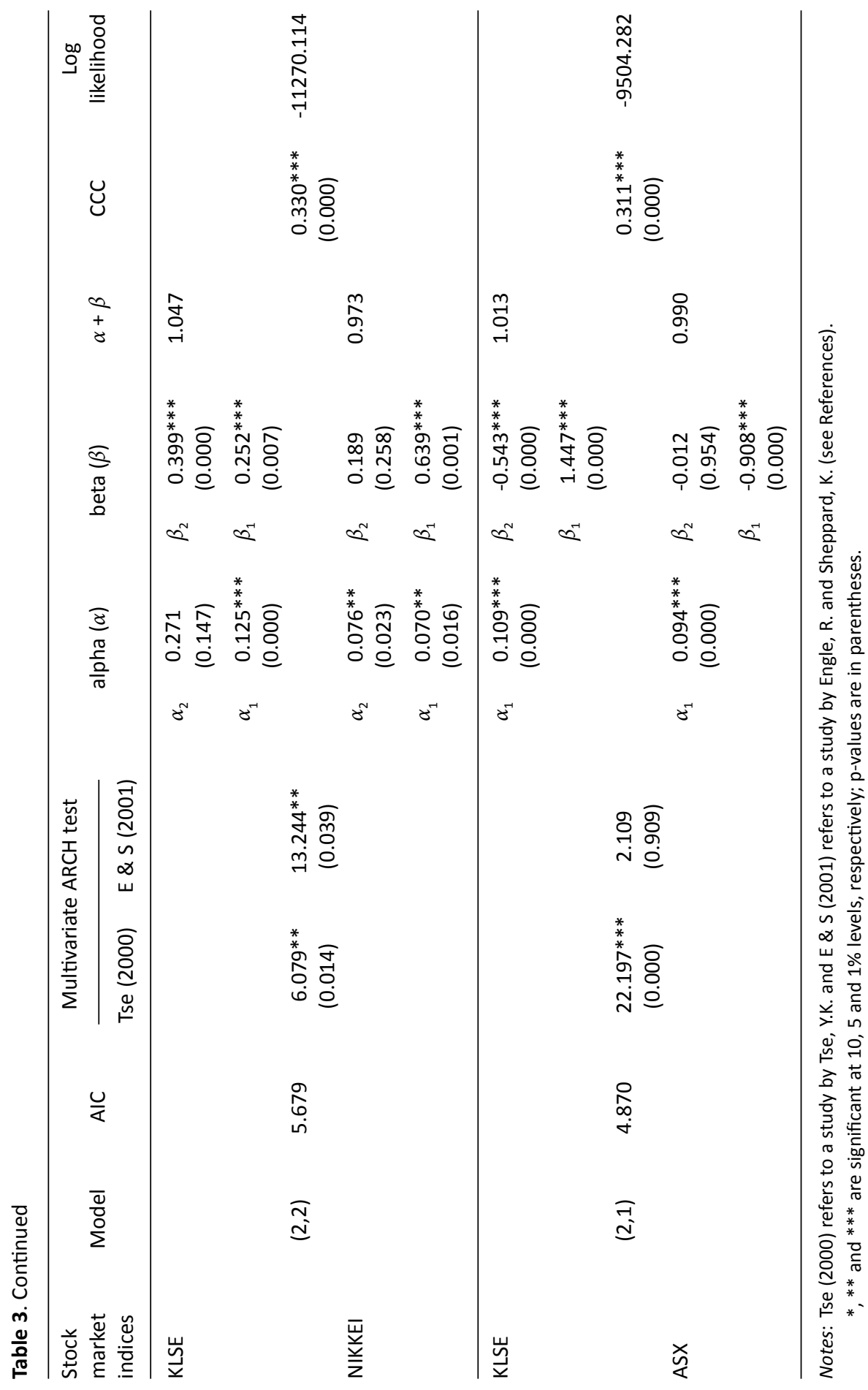


Volatility Integration of Global Stock Markets with the Malaysian Stock Market

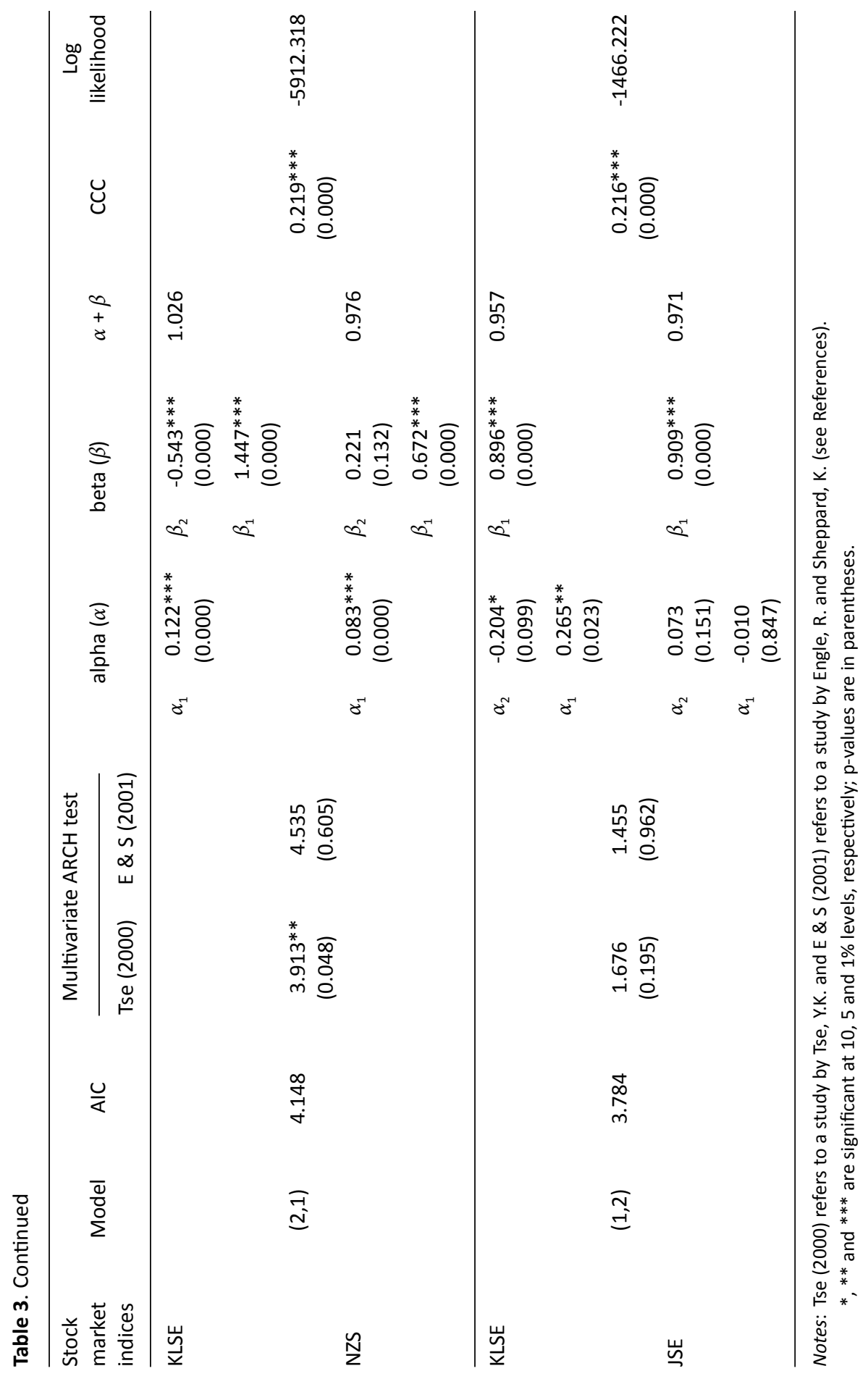


Peh Ying Qian and John Francis Diaz

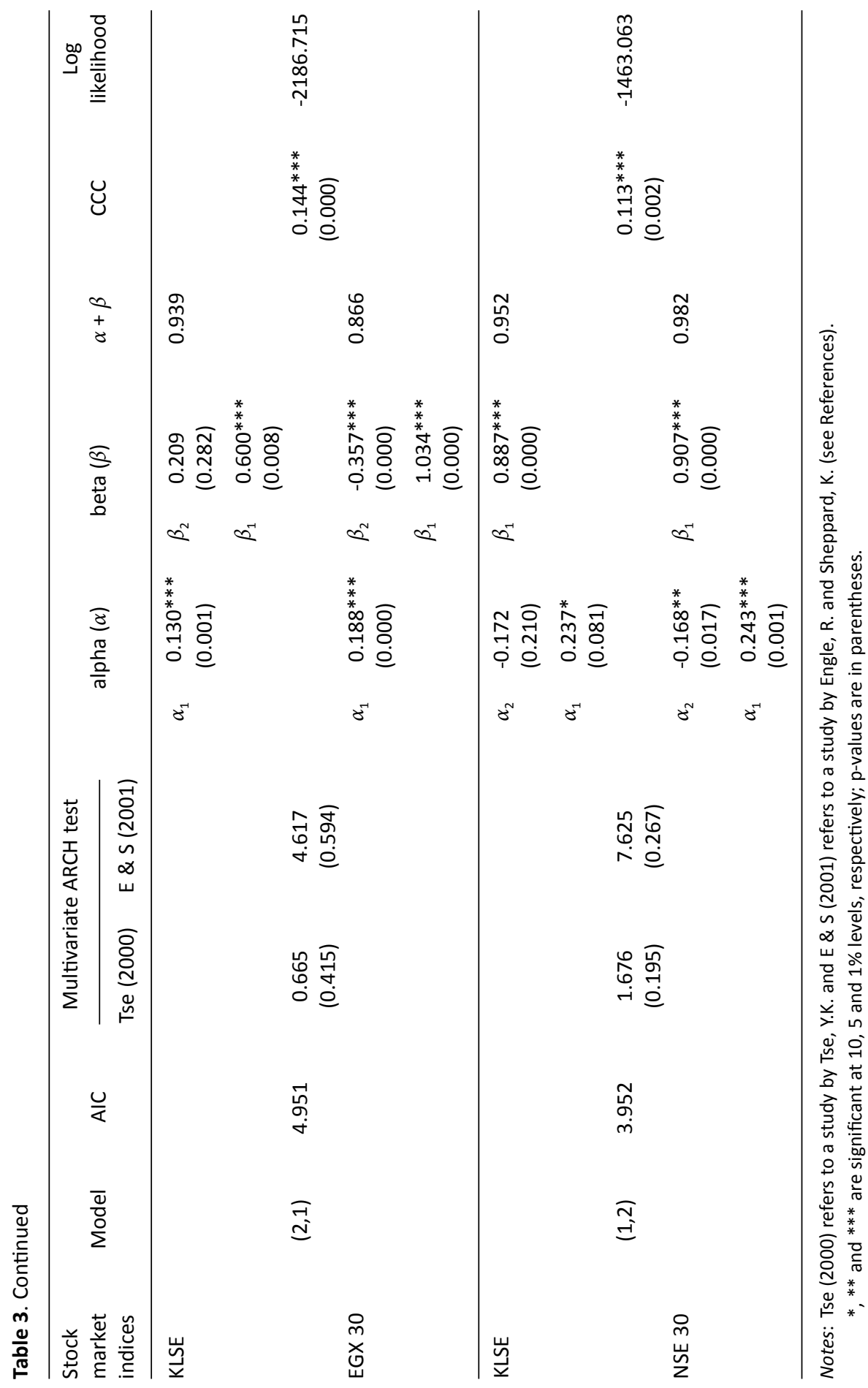


consistent with the previous findings of Li and Giles (2013), Padhi and Lagesh (2012) and Liu (2007) for the volatility spillover experienced by Japan, India and mainland China respectively. Results of alpha + beta are larger than $1(\alpha+\beta>1)$ in most of the country pairings to satisfy the conditions of Quasi Maximum Likelihood Estimator (QMLE). The CCC coefficients all present significant results for every stock market index paired with the KLSE, except for the pairings which do not satisfy the initial multivariate $\mathrm{GARCH}$ tests. The CCC estimates confirm constant return volatility relationships among stock exchanges of these economies in the long-term.

Generally, criticism of the CCC model is its assumption of having constant or nonchanging relationship between economies' volatility. The presence of dynamic or changing volatility relationships can be possibly present because of sudden spikes in volatility as a product of sudden political and economic tensions. Table 4 shows the results of the dynamic conditional correlation (DCC) model among the country pairings considered under study. The lowest AIC again was utilised initially to determine the best fitting lag length for each of the country-pairings. Findings illustrate that most of the best lag order is $(2,2)$, with the exception of Malaysia-India, Malaysia-Nigeria and Malaysia-Indonesia pairings, which are best modelled by the $(1,2)$ order; and MalaysiaAustralia, Malaysia-New Zealand and Malaysia-Egypt pairings, which are best modeled by $(2,1)$ orders. The tests suggested by Tse (2000) and Engle and Sheppard (2001) were used to examine if the multivariate $A R C H$ effects are present in the indices for CCC model, while Hosking (1980) and Li and McLeod (1981) were used for DCC. Findings showed that most of the indices are applicable for the time-series using DCC, with the exception of Malaysia's pairings with the stock markets of Japan, Australia, New Zealand, Egypt and Nigeria.

The table further illustrates that most of the ARCH $(\alpha)$ and GARCH $(\beta)$ estimations showed significant results, which means long-run persistence does exist among these countries indices with the Malaysian index. For example, the changes and shocks in the volatility series of KLSE index can also be affected by the US'S S\&P 500 and DOW, Canada's TSX, UK's FTSE, Germany's DAX, France's CAC 40, India's BSE, China's SSEC and South Africa's JSE. Similar to the CCC model, results of alpha + beta mostly satisfy the conditions of Quasi Maximum Likelihood Estimator (QMLE). Significant DCC coefficients that were consistent with the initial CCC estimates are the stock market pairings of KLSE and FTSE 100 of the UK (0.957); while KLSE and BSE of India (0.734) confirm a longterm volatility relationship. Both the short-term and long-term volatility relationships of the KLSE and DAX of Germany (0.016 and 0.961, respectively); KLSE and CAC 40 of France (0.011 and 0.972, respectively); and KLSE-SSEC of mainland China (0.030 and 0.911 , respectively) were also captured by the DCC model. These three stock markets have relatively stronger trading relations with the Malaysian market because volatility relationships exist in both the short term and long term.

\subsection{Economic Significance of Constant and Dynamic Volatility Linkage}

The long-term volatility relationships of the KLSE with FTSE 100, DAX and CAC 40 found in both the CCC and DCC models are a result of long-term FTAs signed between Malaysia and the respective European countries. Khandekar (2013) explained that the FTAs have 
Peh Ying Qian and John Francis Diaz

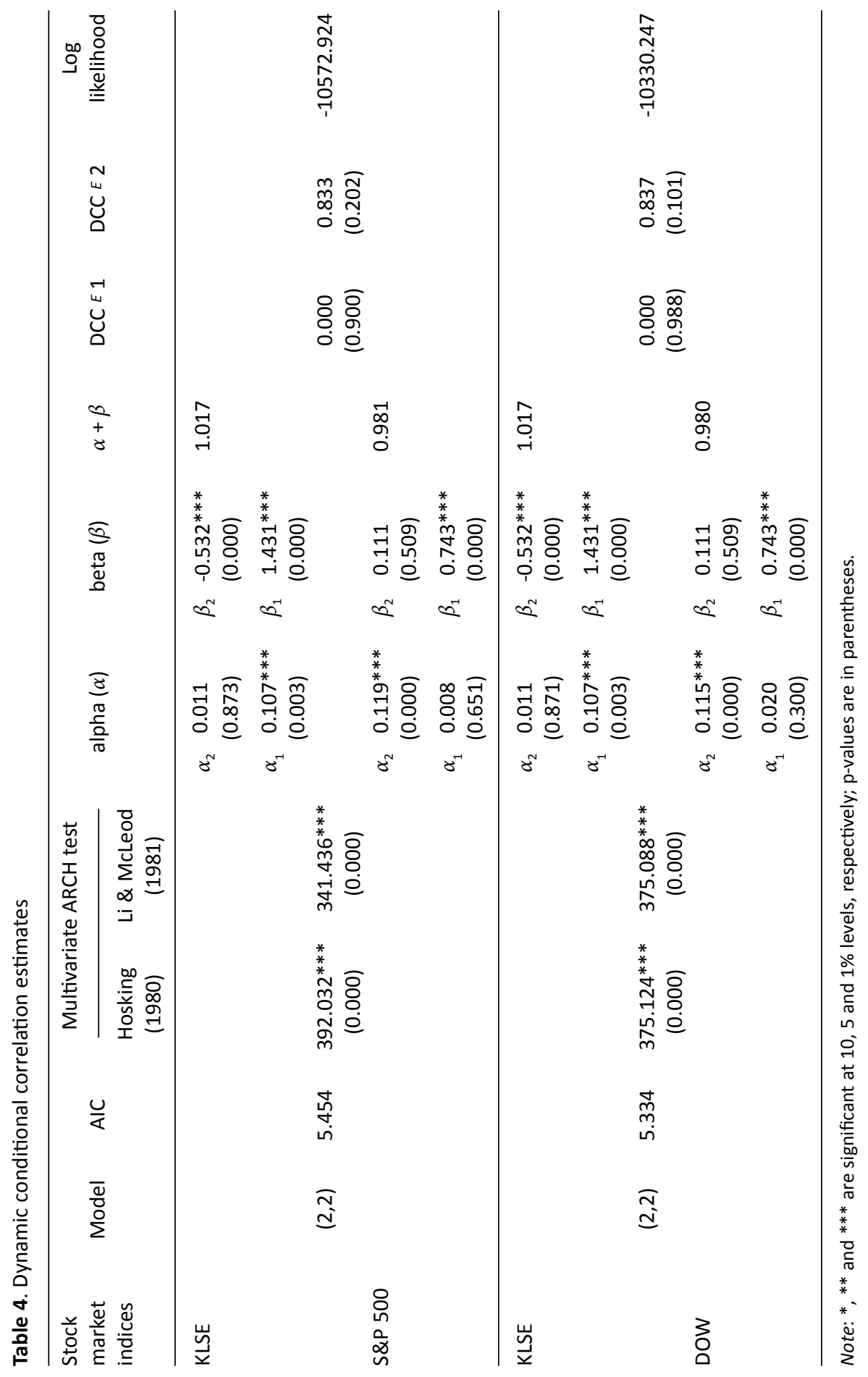


Volatility Integration of Global Stock Markets with the Malaysian Stock Market

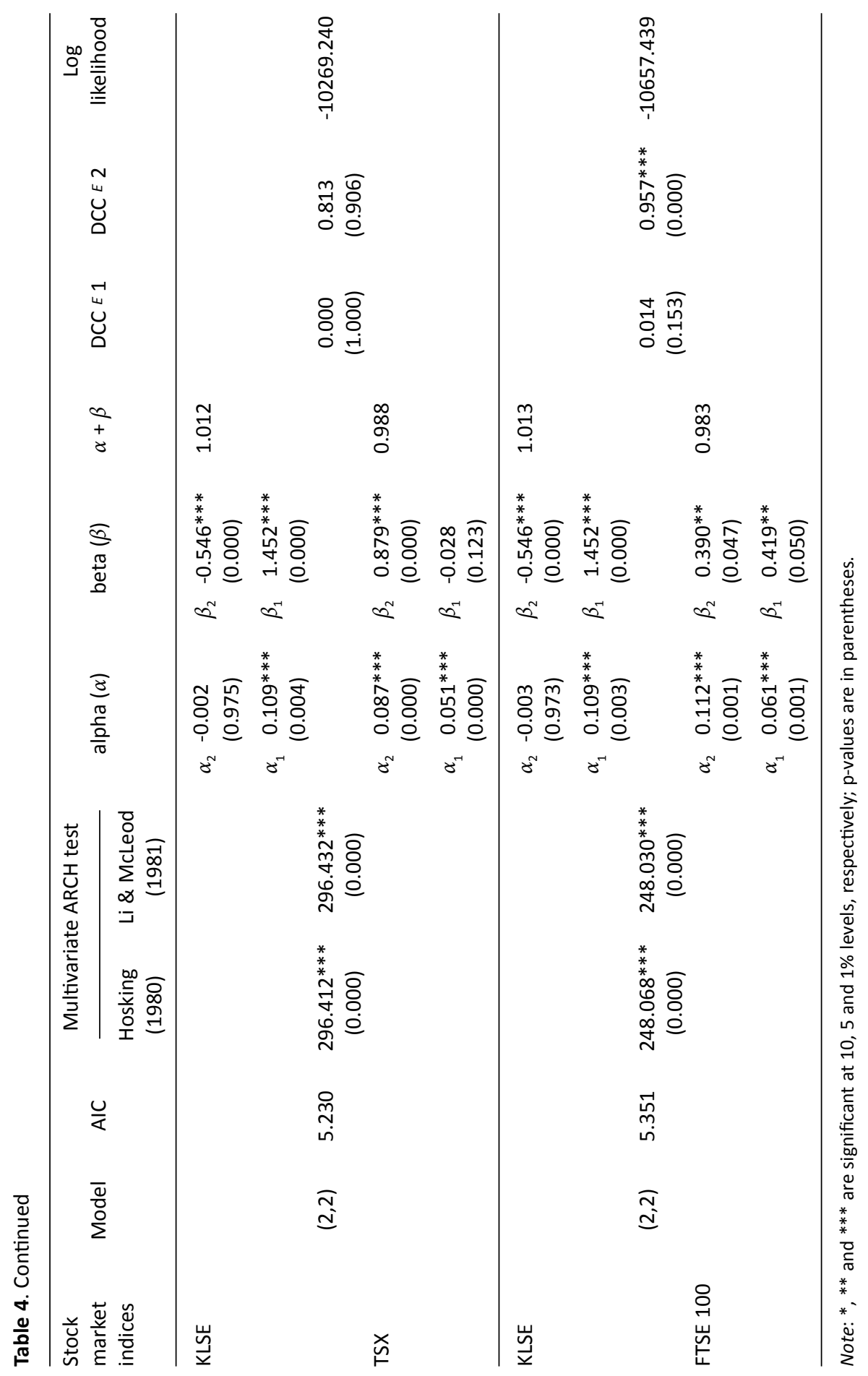


Peh Ying Qian and John Francis Diaz

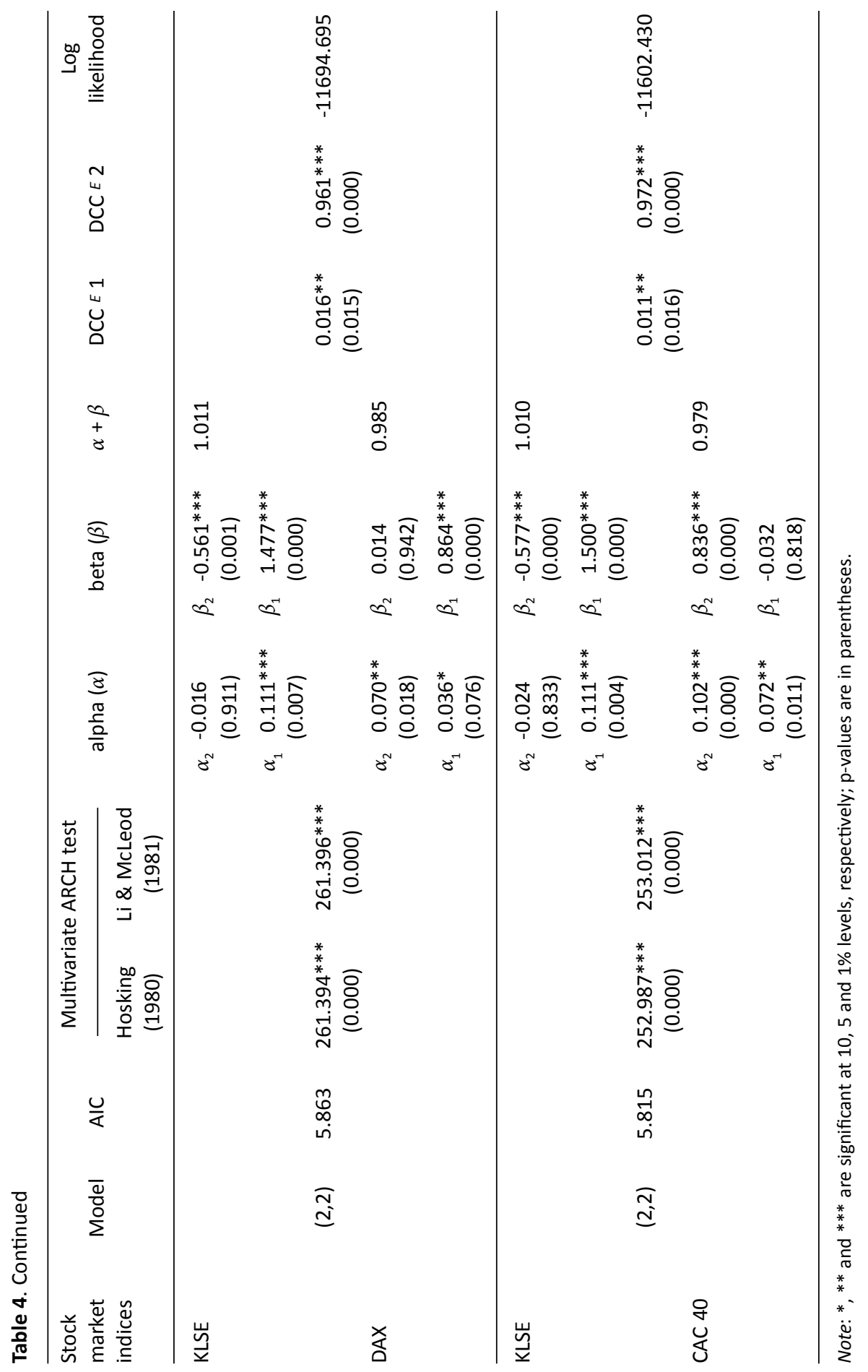


Volatility Integration of Global Stock Markets with the Malaysian Stock Market

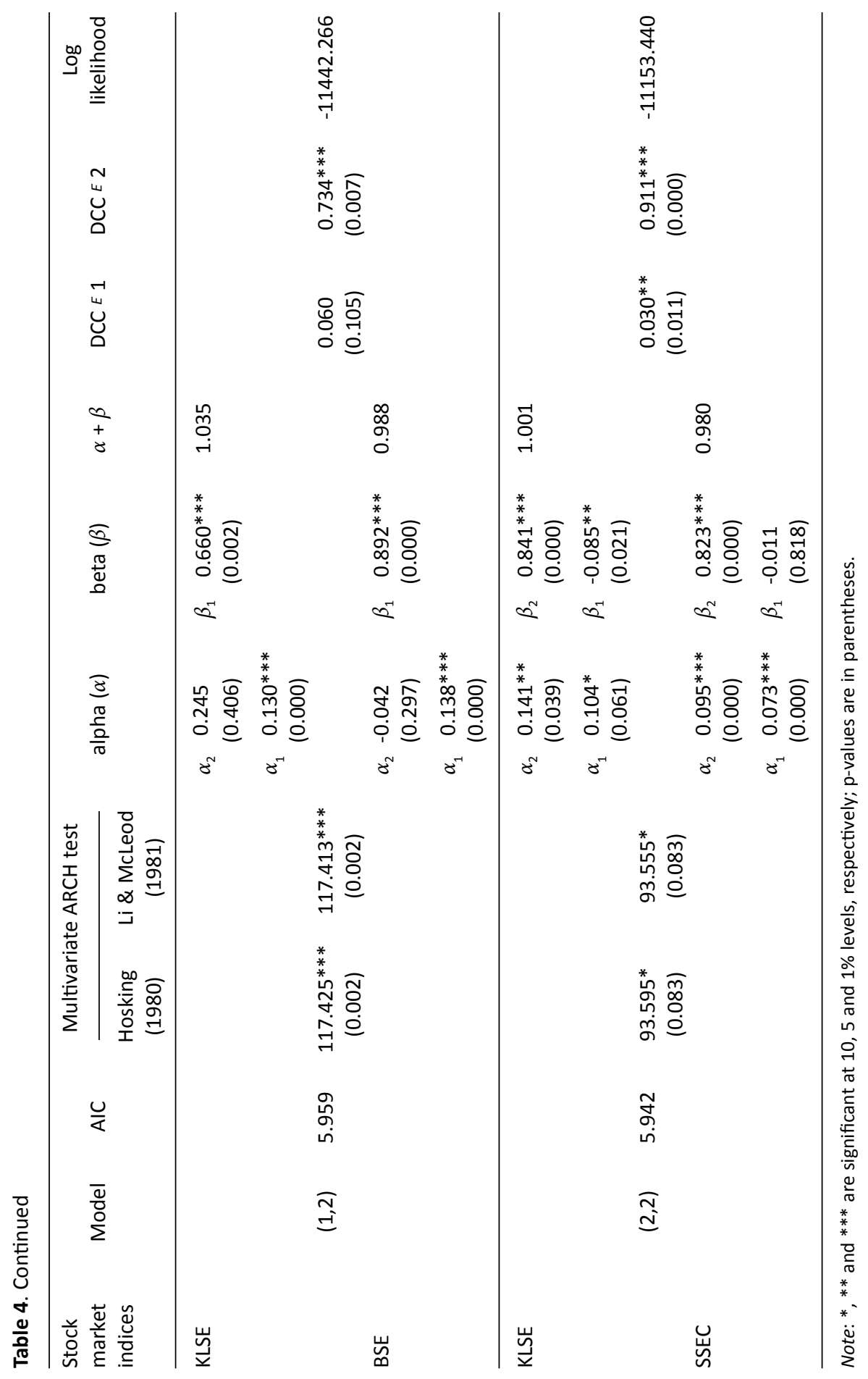


Peh Ying Qian and John Francis Diaz

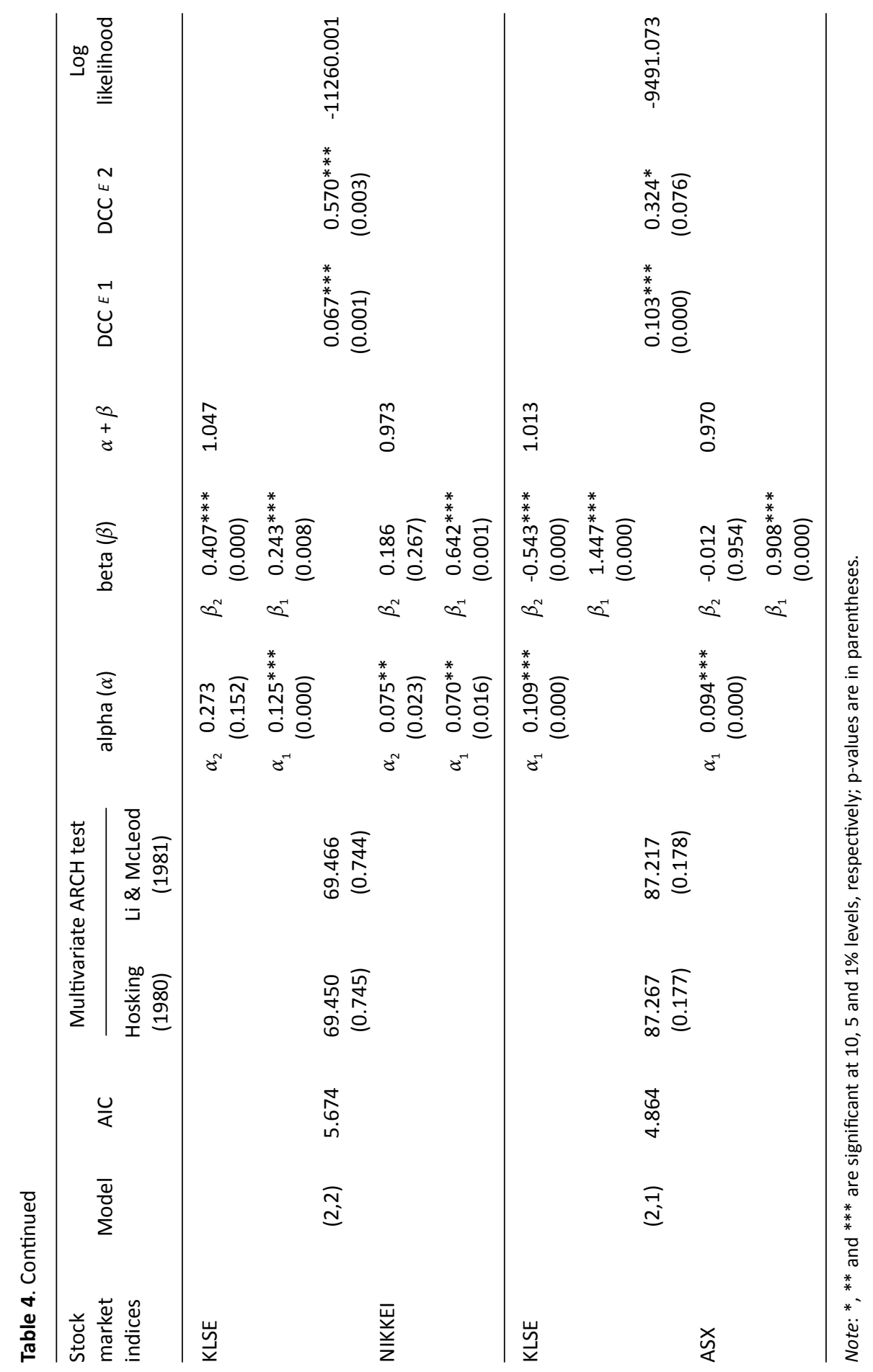


Volatility Integration of Global Stock Markets with the Malaysian Stock Market

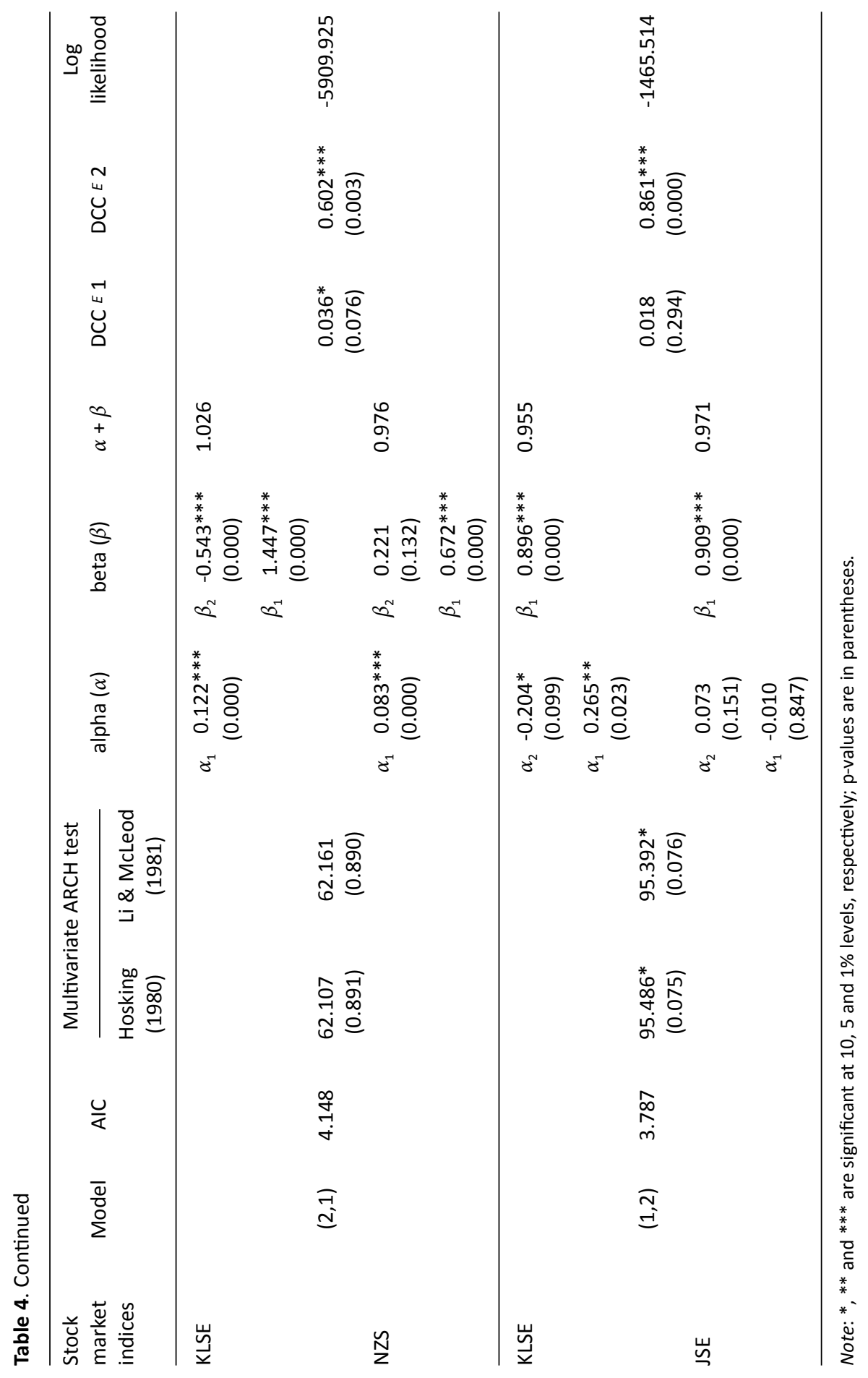


Peh Ying Qian and John Francis Diaz

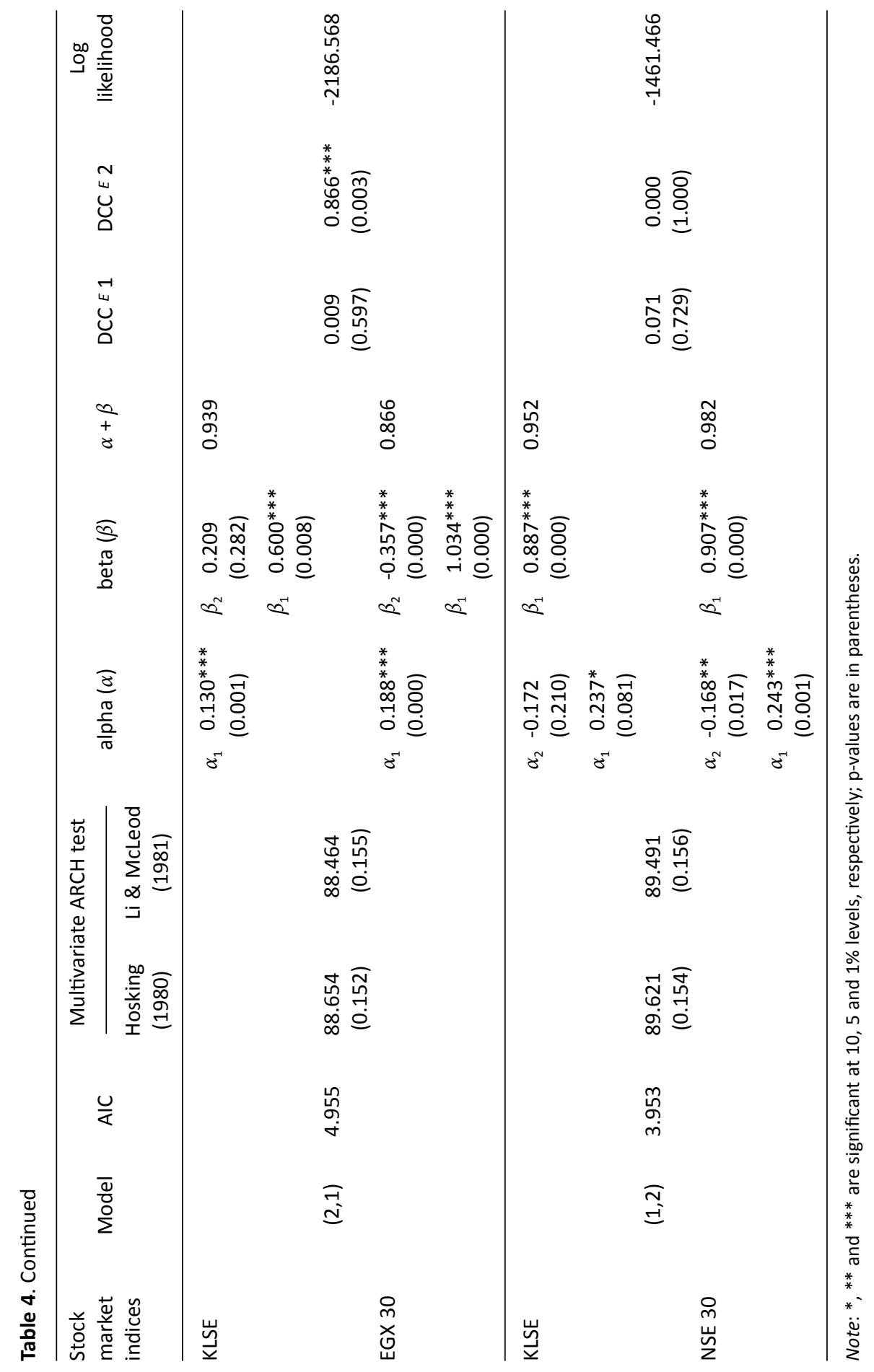


largely contributed to strengthening the trading relationships among these countries, which is consistent with the earlier findings of Melvin and Peiers (2003) research on volatility spillovers from Europe (i.e., UK, Germany and France) to Asian countries. As mentioned earlier the volatility relations between the KLSE and the BSE of India can be a product of the Malaysia-India Comprehensive Economic Cooperation Agreement, and is consistent with previous studies of Padhi and Lagesh (2012), and Mukherjee and Mishra (2008) on the volatility spillover linkage between India and Malaysia.

The dynamic volatility relationship between Malaysia and China's stock markets, as represented by the significant short-run coefficient of 0.030 , and significant long-run coefficient of 0.911 can be attributed to the unstable situation in the South China Sea, wherein China is claiming territories in the submerged reef under turquoise seas about 80 kilometres off Malaysia's Borneo island state of Sarawak. According to Reuters, Malaysia has been playing down security concerns in pursuit of better economic ties with its biggest trade partner, China, but the dispute may prove volatile situations are ahead.

The DCC model identified significant volatility linkage between the KLSE and South Africa's JSE, which is represented by 0.861 . This can be attributed to the implementation of the Malaysia-Africa Business Forum in 2011 (MATRADE, 2011), which will enhance Malaysia's investments in South Africa in petro-chemicals, telecommunications, real estate and tourism. Volatility relations also exist between Malaysia and Canada's stock markets, and this can be attributed to Malaysia as being Canada's third largest commodities trading partner among the ASEAN countries according to the High Commission of Canada (2014).

\subsection{Own Lag and Cross-volatility Relations}

Table 5 shows the results of the diagonal BEKK model among the country pairings that this study considered. Initially, the lowest AIC was utilised to decide on the best lag length that suits each model. Results demonstrate that most of the best lag order is $(1,2)$, with the exception of the Malaysia-Australia pair, which is best modelled by the $(1,1)$ order.

The test proposed by Hosking (1980) and Li and McLeod (1981) were used to verify if the multivariate $A R C H$ effects are present in the indices. Results showed that most of the indices are applicable for the time-series using diagonal BEKK, with the exception of Malaysia's volatility pairings with the stock indices of Australia, New Zealand and Nigeria.

The table illustrates mostly statistical significant values of parameters $A$ and $B$ matrices, plus the $C$ matrix, which contains the diagonal BEKK model. The values of $A$ matrix (alpha numbers) signify that conditional variances only depend on their own lags, in which current return volatilities can be defined by their own lagged values. Results showed that the stock prices of Malaysia's KLSE are significantly affected by its own lagged volatilities; and this is also the case with most of the remaining indices. On the other hand, the values of $B$ matrix (beta numbers) imply that conditional covariance of these stock market returns are also a function of lagged covariance or the lagged cross-products of the shocks among the thirteen stock markets. This means that their volatilities are not only determined by their own lagged values, but cross-volatility 


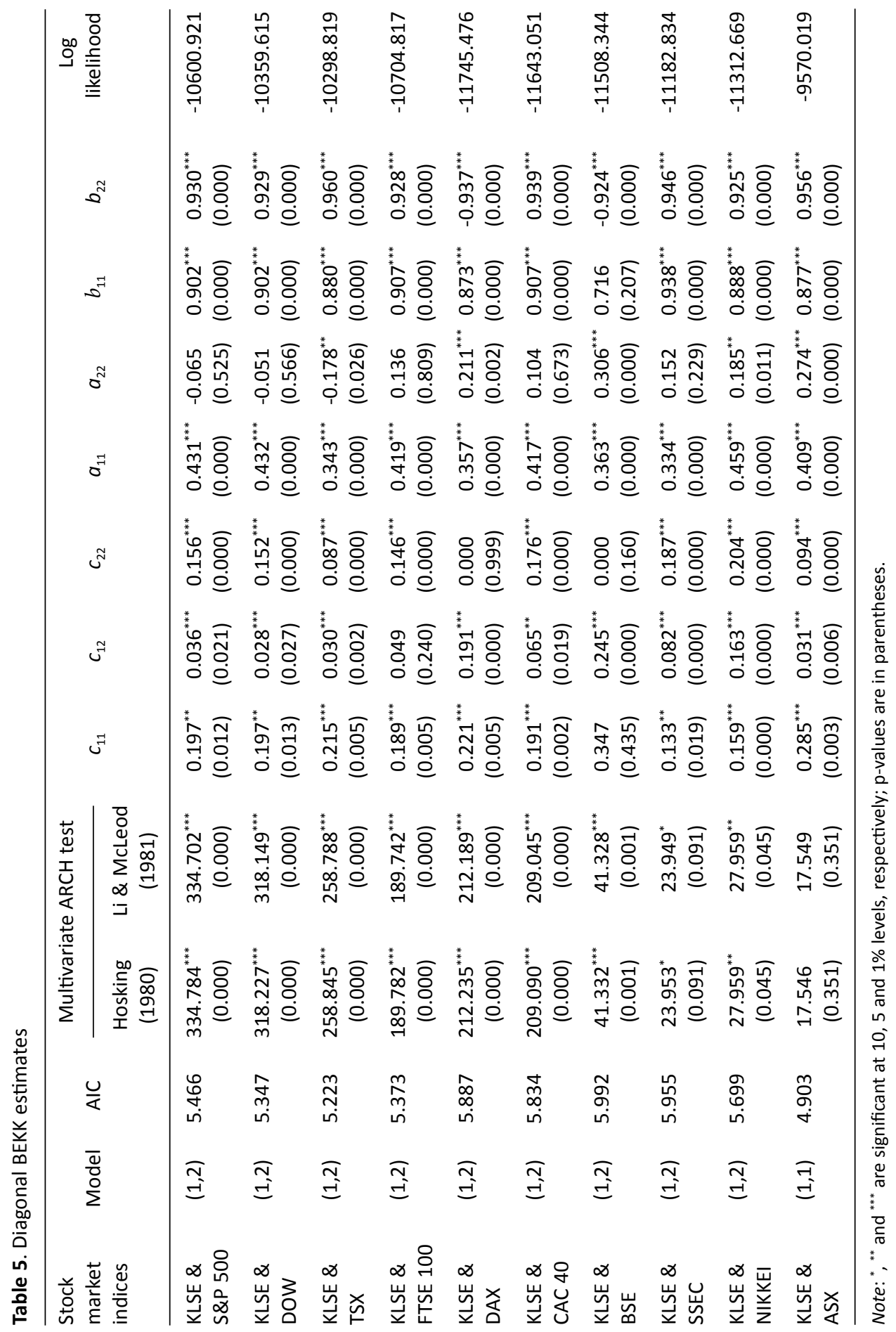


Volatility Integration of Global Stock Markets with the Malaysian Stock Market

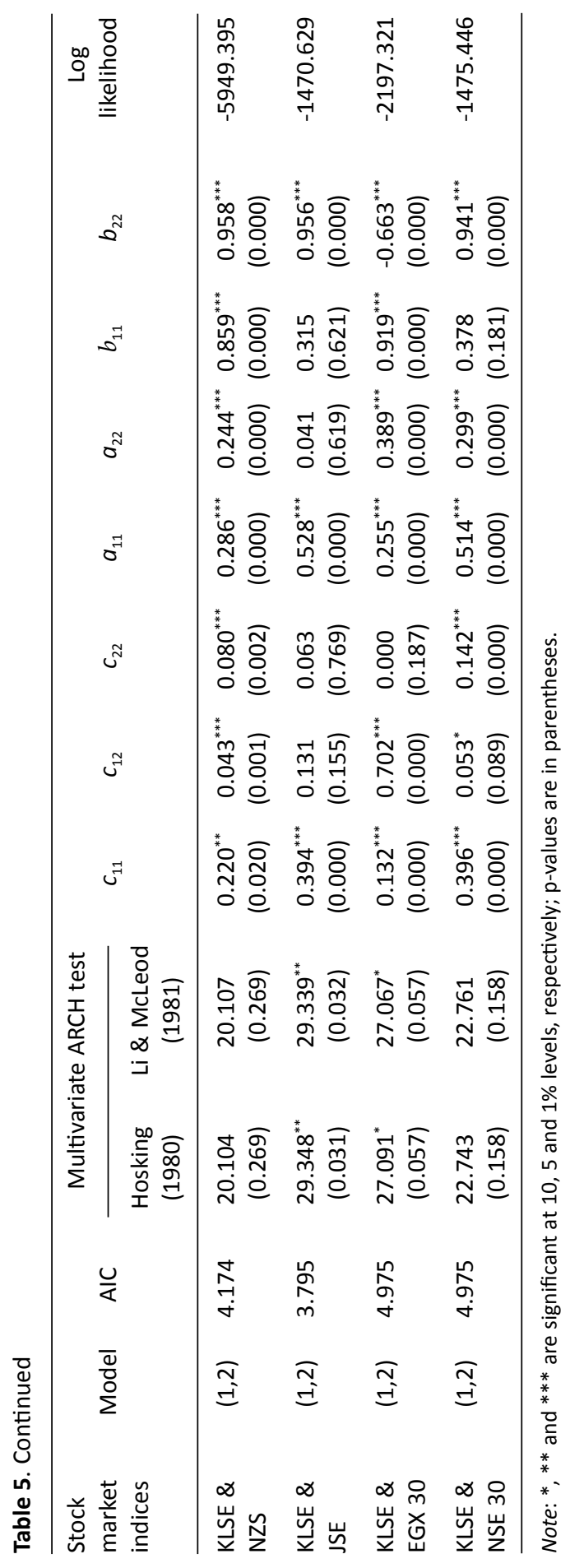


spillovers from other countries are also happening at the same time. Empirical results showed that most of the indices presented significant spillover effects from other countries' lagged volatilities on the stock market of Malaysia's KLSE, which confirms evidence of growing market integration in terms of volatility.

The significant findings of the $C$ matrix confirm the results of both $A$ and $B$ matrices. This proves that the diagonal BEKK model captures the cross-volatility relationships of these countries' major stock market indices. These findings verify that most of the indices have a significant volatility relationship with Malaysia's KLSE, which are consistent with the previous findings of Li and Giles (2013), Mahomed (2013) and Padhi and Lagesh (2012) for Japan, South Africa and India, respectively.

\subsection{Economic Significance of Volatility Spillovers}

The world's economy, particularly its financial markets, has become more integrated and interdependent with the establishment of economic agreements resulting in ripples with no regard to physical boundaries. Heaney and Hooper's (1999) study established that financial market connection is possible through economic trade agreements. Looking at the Asia-Pacific Economic Cooperation (APEC), the authors argued that current and future cash flows generated by companies within might become highly correlated as a result of the agreement, and that market returns might be partially explained by regional returns. In line with this, Hooy and Goh (2010) also mentioned that these correlations are possible, because provisions of trade agreements such as the North American Free Trade Agreement (NAFTA) and the ASEAN (Association of Southeast Asian Nation) Free Trade Agreement (AFTA) call for lowered and removed barriers to equity transactions such as payments of dividends, interest and capital gains among members. The relationship between both the US's S\&P 500 and Dow stock indices support the study of $\mathrm{Ng}$ (2000) on the volatility transmission from the US stock market to the Pacific countries, which supports the significant variance linkage between the US and Malaysian markets. This is attributed to the strong trading relationship between the two countries. Malaysia is one of the top 18 main suppliers of US imports and top 25 largest markets for US exports, while the US ranked top 4 in both Malaysia's export and import markets (Rinehart, 2014). Both countries' governments should work hard in order to maintain this trading relationship in order to enhance the economic growth and to further fulfil the demands of global customers. On one hand, according to the High Commission of Canada (2014), volatility relations that exist between Malaysia and Canada's markets can be a result of Malaysia being Canada's third largest commodities trading partner among the ASEAN countries, with bilateral trade volume that reached approximately US\$3 billion while Canadian commodities export to Malaysia were valued at nearly US\$780 million in 2013. The countries could strengthen their trading volume in the electrical equipment and machinery sector as this is one of the most popular commodity that is being traded between countries.

The Free Trade Agreement (FTA) signed between Malaysia and European countries in 2010 has widely contributed to building up a strong trading relationship among these economies (Khandekar, 2013). Most of the merchandises being traded between the countries are machinery and transport equipment as well as animal and vegetable 
oils. The government should reinforce increasing the trading volume on these sectors in order to improve trade relationship. Additionally, volatility relations between the KLSE and the BSE of India can be a product of the Malaysia-India Comprehensive Economic Cooperation Agreement, which facilitated and enhanced bilateral trade in commodities, services, and investment as well as economic relations between the countries. The previous studies of Padhi and Lagesh (2012), and Mukherjee and Mishra (2008) also illustrated the volatility spillover linkage between India and Malaysia. The governments should further cooperate in the development of the palm oil industry, man-made fabrics, food items, and trade of machineries that process these products. The significant volatility transmission linkage between mainland China and Malaysia's stock markets has been explained earlier by Liu (2007) through the elevation of the Framework Agreement on Comprehensive Economic Cooperation that was signed by China and ASEAN in year 2002 (MITI, 2012). Since most of the merchandise traded between China and Malaysia are intra-industry commodities, this paper suggests that both governments should cooperate more in other sectors such as high-tech industries and financial service sectors. The study of Li and Giles (2013) explains the strong volatility linkage between the Malaysian and Japanese stock markets. The Japan-Malaysia Economic Partnership Agreement is the free trade agreement that was signed and implemented by Japan and Malaysia in 2006. This agreement has partial restrictions on trading, which could enhance the trading relationship in the long term (Rahman, Molla, \& Murad, 2008). It is further recommended that the government should encourage exporters and importers by providing incentives such as tariffs and quota adjustments to boost the trading relationship.

In comparing the best fitting models among the MGARCH models, this study utilised the log-likelihood values. Between the DCC and CCC models, most of the highest log-likelihood values prefer the DCC model, with the exception of KLSE's pairings with the US'S S\&P 500 and DOW as well as Canada's TSX. Log-likelihood values for the above pairings showed similar results in both DCC and CCC models. On the other hand, the log-likelihood values of BEKK model are also lower than the DCC model. This paper concludes that the DCC model is best suited among the country pairings, which is consistent with the earlier studies of Su and Huang (2010) because it captures both short- and long-run volatility changes.

\section{Conclusion}

Malaysia as one of the fastest growing economy among Southeast Asia countries have attracted substantial foreign investment as well as developing and maintaining trading relationships with countries all over the world. This paper utilised three different multivariate GARCH models to examine volatility dynamics across five different regions all over the world from January 5, 1999 to March 13, 2015. Volatility transmission determination plays an important role in verifying correlations among countries' economy and stock markets. The CCC model present significant findings for every stock market index paired with the KLSE index, which confirms constant return volatility relationships among stock exchanges of these economies in the long term. However, a criticism of the CCC model is its assumption of having non-changing relationship 
between stock returns' volatility. The existence of changing volatility relationships can possibly be present in times of sudden political and economic tensions. For example, the dynamic volatility relationship between Malaysia and China's stock markets, can be due to the unstable situation in the South China Sea, where China is claiming territories near Malaysia's Borneo island state of Sarawak. On the other hand, steady long-term volatility relationships between Malaysia's main stock index and the UK's FTSE 100, Germany's DAX and France's CAC 40 as found in the CCC and DCC specifications are attributed to the long-term FTA signed between Malaysia and the European countries.

Similar findings were observed in Malaysia's steady economic relationships with other countries' stock markets, which are products of strong trading and investment partnerships like the significant volatility linkage between Malaysia and South Africa's JSE, which can be attributed to the implementation of the Malaysia-Africa Business Forum enhancing Malaysia's investments in South Africa in petro-chemicals, telecommunications, real estate and tourism. The BEKK model confirms these volatility relationships and adds that these stock markets' volatilities are affected by their own lagged volatilities, and cross-lagged covariance from other stock markets. The loglikelihood values identified the best fitting model among the three MGARCH models applied, which favours the DCC model over the CCC and BEKK estimations. This confirms the fact that the DCC model is better in judging volatility dynamics in global stock markets due to rapid economic growth and increase of globalisation among regions. These results can provide economic significance to the investing community, especially traders in stock markets as a possible basis for investing strategies in Malaysia. Furthermore, the public or even the government can have a better knowledge of the volatility transmission linkages between Malaysia and global regions. Among the academe, researchers can gain new insights in the volatility spillover relationships among different regions, particularly those with few studies in the literature, which can provide wider avenues for future research.

This paper has included 15 stock market returns to represent five different continents. Although it has considered a number of major stock markets, the study still cannot claim a global representation. Our study only included Malaysia, the United States, Canada, the United Kingdom, Germany, France, Australia, New Zealand, Japan, China, India, South Africa, Nigeria and Egypt which ignores other countries especially from the developing economies. As the emerging markets become increasingly integrated globally, these economies should not be underestimated. Further studies are suggested to include more emerging stock markets to gain a more global stock market relationship.

The study also centred on the pairings of the KLSE index with other major stock markets. However, other possible market pairings (e.g., France-Nigeria, Australia-India and Canada-Egypt) are very much possible and can provide substantial information, but were not covered. Thus, it is suggested that future studies consider other market relationships to get wider results. Another perceived limitation is the lack of creating a more solid connection in the literature with findings coming from less common countrypairings for our research. For example, to the best of our knowledge, no studies have yet been done on the relationship of Malaysia's stock market with the financial markets 
of South Africa, Egypt and Nigeria because most of the previous researches emphasise the linkage between Malaysia and the US, Japan, China, India and other ASEAN countries. Therefore, the limitation of providing a better connection with previous literature is expected. Nevertheless, this paper can advance knowledge by providing fresh information among the less common market pairings for the investing public.

Methodology limitations were also identified, MGARCH models applied cannot capture important data characteristics like volatility asymmetries and leverage effects. The extant literatures have been adamant in stressing the importance of identifying these properties, because negative shocks have a wider impact on volatility than positive news. These multivariate models cannot also control external factors (i.e., stronger Asian economies like China, India and Japan) that might affect volatility relationships of Malaysia to other non-major players. Future theoretical and empirical studies can augment the MGARCH models to capture the above mentioned limitations by adding models that cover asymmetries, leverage effects, and control of other variables. The relatively few number of studies using MGARCH models will again limit the research in providing better literature connection in our future findings. However, this paper can again provide extensions that will push topic boundaries for the academic community.

\section{References}

Allen, D.E., Amram, R., \& McAleer, M. (2013). Volatility spillovers from the Chinese stock market to economic neighbours. Mathematics and Computers in Simulation, 94(August), 238-257.

Alotaibi, A.R., \& Mishra, A.V. (2015). Global and regional volatility spillovers to GCC stock markets. Economic Modelling, 45(February), 38-49.

Ang, J.B. (2008). Determinants of foreign direct investment in Malaysia. Journal of Policy Modeling, 30(1), 185-189.

Bauwens, L., Laurent, S., \& Rombouts, J. (2006). Multivariate GARCH models: A survey. Journal of Applied Econometrics, 21(1), 79-109.

Bollerslev, T. (1990). Modeling the coherence in short-run nominal exchange rates: A multivariate generalized ARCH model. Review of Economics and Statistics, 72(3), 498-505.

Caporin, M., \& McAleer, M. (2009). Do we really need both BEKK and DCC? A tale of two covariance models (Social Science Research Network eLibrary, February 5, 2009). Retrieved from https://ssrn.com/abstract $=1338190$

Chang, C-L., McAleer, M., \& Tansuchat, R. (2011). Crude oil hedging strategies using dynamic multivariate GARCH. Energy Economics, 33(5), 912-923.

Duasa, J., \& Kassim, S.H. (2008). Foreign portfolio investment inflows and economic performance in Malaysia: A disaggeregated analysis. Gadjah Mada International Journal of Business, 10(3), 313-330.

Engle, R. (2002). Dynamic conditional correlation: A simple class of multivariate GARCH models. Journal of Business \& Economic Statistics, 20(3), 339-350.

Engle, R., \& Kroner, F. (1995). Multivariate simultaneous generalized ARCH. Econometric Theory, 11(1), 122-150.

Engle, R., \& Sheppard, K. (2001). Theoretical and empirical properties of dynamic conditional correlation multivariate GARCH (Economics Working Paper Series). La Jolla, CA: University of California San Diego.

Heaney, R., \& Hooper, V. (1999). World, regional and political risk influences upon Asia-Pacific equity market returns. Australian Journal of Management, 24(2), 131-142. 
High Commission of Canada. (2014). Canada - Malaysia Relations (Bilateral Relations Report). Retrieved from http://www.canadainternational.gc.ca/malaysia-malaisie/bilateral_relations_ bilaterales/canada-malaysia-malaisie.aspx?lang=eng

Hooy, C.W., \& Goh, K.L. (2010). Exposure to the world and trading-bloc risks: A multivariate capital asset pricing model. Research in International Business and Finance, 24(2), 206-222.

Hosking, J. (1980). The multivariate portmanteau statistic. Journal of the American Statictical Association, 75(371), 602-608.

Ibrahim, M. (2010). Islamic finance and Malaysia's role. Paper presented at the 21st Conference of Presidents of Law Associations in Asia, Kuala Lumpur, Malaysia. Retrieved from http:// www.bis.org/review/r100803f.pdf

Khandekar, G. (2013). EU-Asia trade: In need of a strategy (Paper published by Fundación para las Relaciones Internacionales y el Diálogo Exterior). Retrieved from http://fride.org/download/ PB_13_EU_Asia_trade.pdf

Korkmaz, T., Çevik, E.i., \& Atukeren, E. (2012). Return and volatility spillovers among CIVETS stock markets. Emerging Markets Review, 13(2), 230-252.

Krause, T., \& Tse, Y. (2013). Volatility and return spillovers in Canadian and U.S. industry ETFs. International Review of Economics \& Finance, 25(January), 244-259.

Lean, H.H., \& Teng, K.T. (2013). Integration of world leaders and emerging powers into the Malaysian stock market: A DCC-MGARCH approach. Economic Modelling, 32(May), 333-342.

Li, W., \& McLeod, A. (1981). Distribution of the residual autocorrelation in multivariate ARMA time-series models. Journal of the Royal Statictical Society. Series B: Statistical Methodology, 43(2), 231-239.

Li, Y., \& Giles, D.E. (2013). Modelling volatility spillovers effects between developed stock markets and Asian emerging stock markets (Econometrics Working Papers, No. 1301). Victoria BC, Canada: University of Victoria.

Liu, L. (2007). Volatility and mean spillover from the US and China to ASEAN (Department of Economics and Management, Lund University, Sweden). Retrieved from http://lup.lub.lu.se/ student-papers/record/1848804

Mahomed, F. (2013). S. Africa - Malaysia trade relations show substantial growth over the last 20 years (CNBC Africa online article). Retrived from: http://www.cnbcafrica.com/news/ southern-africa/2013/08/27/south-africa-malaysia-trade-relations-show-substantial-growthover-the-last-20-years/

Majdoub, J., \& Mansour, W. (2014). Islamic equity market integration and volatility spillover between emerging and US stock markets. The North American Journal of Economics and Finance, 29(July), 452-470.

MATRADE. (2011). Malaysian trade raises awareness on doing business with South Africa (Malaysia External Trade Development Corporation Report). Kuala Lumpur: Author.

McAleer, M. (2005). Automated inference and learning in modeling financial volatility. Econometric Theory, 21(1), 232-261.

Melvin, M., \& Peiers, B. (2003). The global transmission of volaility in the foreign exchange market. Review of Economics and Statistics, 85(3), 670-679.

Ministry of International Trade and Industry. (2012). The Framework Agreement on Comprehensive Economic Cooperation (Malaysia's Free Trade Agreements No. 7). Kuala Lumpur: Author.

Miyakoshi, T. (2003). Spillovers of stock return volatility to Asian equity markets from Japan and the US. Journal of International Financial Markets, Institutions and Money, 13(4), 383-399.

Mukherjee, K.N., \& Mishra, R.K. (2008). Stock market integration and volatility spillover: India and its major Asian counterparts (Munich Personal RePEc Archive paper, No. 12788). Retrieved from https://mpra.ub.uni-muenchen.de/12788/index.html

$\mathrm{Ng}$, A. (2000). Volatility spillover effect from Japan and the US to the Pacific Basin. Journal of International Money and Finance, 19(2), 207-233. 
Padhi, P., \& Lagesh, M.A. (2012). Volatility spillover and time-varying correlation among the Indian, Asian and US stock markets. Journal of Quantitative Economics, 10(2), 78-90.

Patel, S.A. (2013). Dynamic interdependence among Asian equity markets: Empirical evidence from India. Journal of Management Research, 13(4), 219-228.

Rahman, K.M., Molla, R.I., \& Murad, M.W. (2008). Japan-Malaysia Free Trade Agreement: Expectations and achievements. Journal of Comparative International Management, 11(1), 29-42.

Rinehart, I.E. (2014). Malaysia: Background and U.S. relations (Congresional Research Service Report, Vol. 7-5700). Washington DC: Library of Congress.

Silvennoinen, A., \& Terasvirta, T. (2008). Multivariate GARCH models (SSE/EFI Working Paper Series in Economics and Finance, No. 669). Stockholm, Sweden: Stockholm School of Economics.

Singh, P., Kumar, B., \& Pandey, A. (2008). Price and volatility spillovers across North American, European and Asian stock markets: With special focus on Indian stock market (IIMA Working Paper No. 2008-12-04). Ahmedabad, Gujarat: Indian Institute of Management Ahmedabad.

Singh, P., Kumar, B., \& Pandey, A. (2010). Price and volatility spillovers across North American, European and Asian stock markets. International Review of Financial Analysis, 19(1), 55-64.

$\mathrm{Su}, \mathrm{W} .$, \& Huang, Y. (2010). Comparison of multivariate GARCH models with application to zero-coupon bond volatility (Master thesis, Department of Statistics, Lund University, Sweden). Retrieved from https://lup.lub.lu.se/luur/download?func=downloadFile\& recordOId $=1619618 \&$ fileOId $=1619628$

Thao, T.P., Daly, K., \& Ellis, C. (2013). Transmission of the global financial crisis to the East Asian equity markets. International Journal of Economics and Finance, 5(5), 171-183.

Tse, Y. (2000) A test for constant correlations in multivariate GARCH model, Journal of Econometrics, 98(1), 107-127.

UNCTAD. (2014). World Investment Report 2014. Geneva, Switzerland: Author.

Wang, P., \& Moore, T. (2008). Stock market integration for the transition economies: time-varying conditional correlation approach. Manchester School, 76(1), 116-133.

World Bank. (2013). Market capitalization of listed domestic companies (World Federation of Exchanges Database). Retrieved from http://data.worldbank.org/indicator/CM.MKT.LCAP. GD.ZS?locations $=M Y$

Worthington, A., \& Higgs, H. (2004). Transmission of equity returns and volatility in Asian developed and emerging markets: A multivariate GARCH analysis. International Journal of Finance \& Economics, 9(1), 71-80.

Yilmaz, K. (2010). Return and volatility spillovers among the East Asian equity markets. Journal of Asian Economics, 21(3), 304-313.

Yusoff, M.B. (2005). Malaysian bilateral trade relations and economic growth. International Journal of Business and Society, 6(2), 55-68.

Zhou, X., Zhang, W., \& Zhang, J. (2012). Volatility spillovers between the Chinese and world equity markets. Pacific-Basin Finance Journal, 20(2), 247-270. 
